\title{
Unusual variants of malignant melanoma
}

\author{
Cynthia M Magro ${ }^{1}$, A Neil Crowson ${ }^{2}$ and Martin C Mihm $\mathrm{Jr}^{3}$ \\ ${ }^{1}$ Division of Dermatopathology, Department of Pathology, Ohio State University, Columbus, OH, USA; \\ ${ }^{2}$ Departments of Dermatology, Pathology and Surgery, University of Oklahoma and Regional Medical \\ Laboratories, St John Medical Center, Tulsa, OK, USA and ${ }^{3}$ Departments of Dermatology and Pathology, \\ Harvard Medical School, Massachusetts General Hospital, Boston, MA, USA
}

\begin{abstract}
A potential diagnostic pitfall in the histologic assessment of melanoma is the inability to recognize unusual melanoma variants. Of these, the more treacherous examples include the desmoplastic melanoma, the nevoid melanoma, the so-called 'minimal-deviation melanoma,' melanoma with prominent pigment synthesis or 'animal-type melanoma,' and the malignant blue nevus. Also problematic are the unusual phenotypic profiles seen in vertical growth phase melanomas; these include those tumors whose morphological peculiarities mimic cancers of nonmelanocytic lineage and those melanomas that express aberrant antigenic profiles not commonly associated with a melanocytic histogenesis. Metaplastic change in melanoma, balloon cell melanoma, signet-ring cell melanoma, myxoid melanoma, small cell melanoma and rhabdoid melanoma all have the potential to mimic metastatic and primary neoplasms of different lineage derivations. Abnormal immunohistochemical expression of CD 34, cytokeratins, epithelial membrane antigen, and smooth muscle markers as well as the deficient expression of $\mathbf{S 1 0 0}$ protein and melanocyte lineage-specific markers such as GP100 protein (ie HMB-45 antibody) and A103 (ie Melan-A) also present confusing diagnostic challenges. In this review, we will discuss in some detail certain of these novel clinicopathologic types of melanoma, as well as the abnormal phenotypic expressions seen in vertical growth phase melanoma. Modern Pathology (2006) 19, S41-S70. doi:10.1038/modpathol.3800516
\end{abstract}

Keywords: melanoma; variants; phenotype; immunohistochemistry; morphology

\section{Desmoplastic melanoma}

\section{Introduction and Clinical Features}

Demoplastic melanoma is a rare variant of malignant melanoma first recognized in $1971 .^{1}$ Desmoplastic and neurotropic melanoma may be mistaken clinically for a scar, a fibroma, a basal cell carcinoma, or a fibromatosis. Sometimes there is pronounced mucin deposition that imparts a boggy quality to the lesion. ${ }^{2,3}$ The clinical clue to the diagnosis, when present, is cutaneous or mucosal pigmentation overlying a palpable dermal or submucosal nodule. That said, only half of desmoplastic melanomas are clinically pigmented. ${ }^{3}$ Desmoplastic melanomas tend to occur in the head and neck area and the upper back ${ }^{4-7}$ but are also seen in mucosal sites such as the vulva or gingiva ${ }^{8}$ and in acral locations. Typically, they occur in older patients, with mean ages in the larger series falling into the sixth to eighth decades of life. ${ }^{4,6,9-15}$ Larger series show a

Correspondence: Dr C Magro, MD, Division of Dermatopathology, Department of Pathology, Ohio State University, 410 West 10th Avenue, N305 Doan Hall, Columbus, OH 43215, USA.

E-mail: magro-1@medctr.osu.edu

Received 19 September 2005; accepted 28 September 2005 male preponderance of 1.75 to $1 .^{15}$ Although any given desmoplastic melanoma can be deeply invasive, when matched for depth of invasion, they are associated with a lesser risk of metastatic disease than conventional melanomas of similar depth. The classical clinical finding is that of a pale or fleshy firm nodule reminiscent of a scar, which tends to delay clinical diagnosis and biopsy. Carlson et $a l,{ }^{6}$ who reported an equal distribution in men and women, found most tumors to be located in the head and neck area (75\%) and to be nonpigmented (57\%); they concluded that most desmoplastic melanomas took origin in neoplasms that were of lentigo maligna subtype. The lesions show a high recurrence rate, with recurrent tumors typically being amelanotic and presenting as an area of scarring or induration with palpable, ill-defined margins. In patients with multiple recurrences, invasion of adjacent structures such as salivary gland, periosteum, glenoid fossa, and cranial cavity can be seen. ${ }^{9}$ Local recurrences were noted in $29 \%$ of patients in one series of 58 desmoplastic and/or neurotropic melanomas, with a malignant cranial neuropathy occurring in four patients and death from metastatic disease in $19 \%$ of cases. ${ }^{16}$ Neurotropism strongly enhances the statistical likelihood of local 
recurrence. ${ }^{15}$ The probability of 5 -year survival for tumors greater than $4 \mathrm{~mm}$ in thickness is higher than that for other types of melanomas that are of similar thickness, ${ }^{6,17}$ as alluded to above.

\section{Histology}

Desmoplastic melanoma is a form of vertical growth phase melanoma in which the invasive tumor cells have a spindled morphology and are associated with a striking desmoplastic stromal response (Figures 16). There appears to be a morphologic continuum between desmoplastic melanoma and vertical growth phase spindle cell melanoma, the latter being the most frequent type of invasive melanoma seen in lentigo maligna melanoma. In desmoplastic melanoma, the neoplasm tends to extend deeply into the reticular dermis. The average depth of invasion at time of first excision is $4.1 \mathrm{~mm} .^{6}$ Desmoplastic melanoma is poorly circumscribed, with the deep and lateral margins of the tumor being ill-defined (Figure 1). ${ }^{3}$ Reactive fibroblasts, the presumptive source of matrix production, are intimately admixed with the tumor cells, although there is some controversy about the source of stromal collagenization in these neoplasms. The neoplastic melanocytic component may either assume a singlecell dispersal pattern within the sclerotic dermis or be disposed in long fascicles in a fashion reminiscent of a fibrosarcoma, sometimes assuming a whorled or storiform pattern. The fascicles may be ensheathed by a mucinous matrix, imparting an

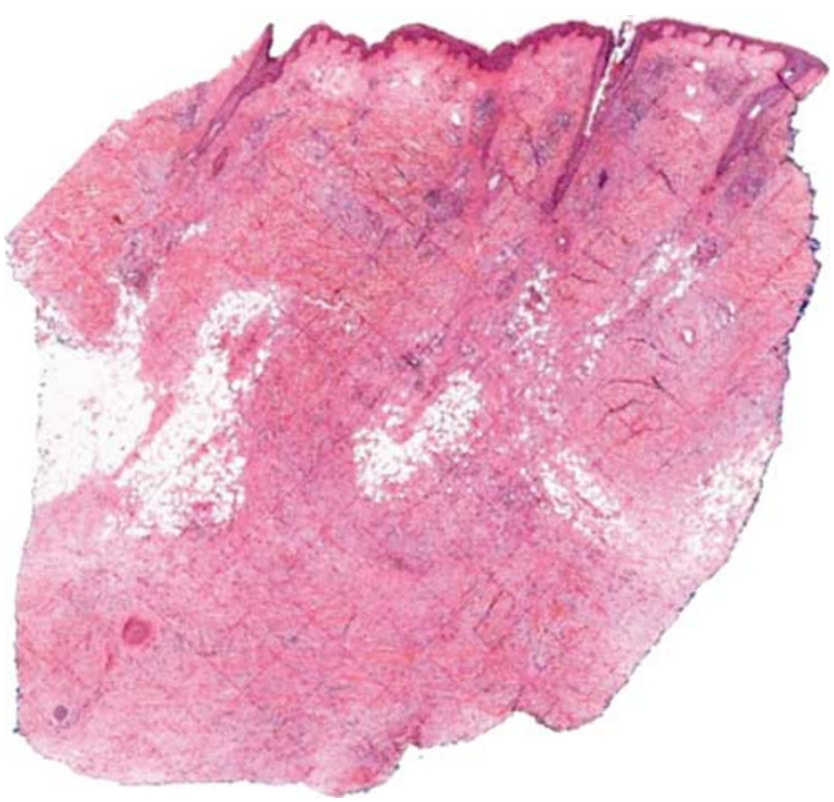

Figure 1 Desmoplastic melanoma: The biopsy has a square contour due to the presence of abundant stromal collagen deposition. It also appears vaguely hypercellular at scanning magnification with extension of a process in and around the subcutaneous fat lobules accompanied by fatty atrophy and extension into the subcutaneous fascia. appearance resembling a peripheral nerve sheath tumor such as a neuroma, schwannoma, or neurofibroma $^{2}$ and prompting misdiagnosis as a form of peripheral nerve sheath tumor ${ }^{18}$ (Figure 3). The spindle cell and collagenous process may lie in intimate apposition to the epidermis, which usually appears attenuated, or there may be a grenz zone. ${ }^{6}$ When the tumor is contiguous with the epidermis, a significantly thinner depth of invasion is the rule. Within the epidermis in up to $80 \%$ of lesions in some series, but in only half in our hands, there is a proliferation of atypical melanocytes (Figures 2 and 4). Most often, this atypical proliferation is present in a lentiginous array; the density and degree of cytologic atypia is consonant with lentigo maligna in $25-50 \%$ of cases. ${ }^{6}$ Rarely, a pagetoid pattern of epithelioid melanocytes consistent with superficial spreading melanoma is seen. Since an intraepidermal component tends not to be identifiable in deeper lesions, ${ }^{6}$ it may be that migration from an intraepidermal to an intradermal location occurs during the evolution of desmoplastic melanoma. Not infrequently, the most superficial aspect of the invasive component may show a nested pattern of dermal infiltration in which the superficial nests are at varying angles to the long axis of the epidermis. In addition, an occasional nest may be seen amidst the dominant spindled sclerotic component. There is usually infiltration of nerves by tumor, which tends to surround and permeate cutaneous nerve trunks, resulting in an endoneurium that appears hypercellular. These infiltrated nerves may be found at significant distances from the main tumor mass including within the subcutaneous fat. ${ }^{19}$ It is prudent to study the nerve trunks in any invasive melanoma but in particular in those neoplasms of lentigo maligna melanoma or acral lentiginous melanoma subtypes. Desmoplastic melanomas may also manifest considerable pagetoid infiltration of the straight eccrine ducts and glands. The cytomorphology of the spindled populace is one of large cells with oval to elongated nuclei that appear hyperchromatic with coarse, irregularly distributed chromatin and conspicuous nucleoli. The attenuated cytoplasmic processes merge with the background stroma (Figure 5). There may be individual cell necrosis. Mitoses are identified throughout the tumor, although the mitotic index is usually low, averaging approximately two mitoses per 10 highpower fields. In one series, 10 of 28 cases exhibited no mitoses; ${ }^{6}$ this has been our experience as well. The tumor cells are usually devoid of pigment, although there are often occasional melanophages scattered through the stroma. There are rare reports, however, of heavily melanized neurotropic melanomas in which perineural collections of pigmentcontaining cells were seen. The presence of nodular chronic inflammatory cell infiltrates along with mucinotic zones $^{2}$ (Figures 3 and 6), the latter in rare cases so extensive as to lead to a misdiagnosis of focal cutaneous mucinosis, complete the picture. 


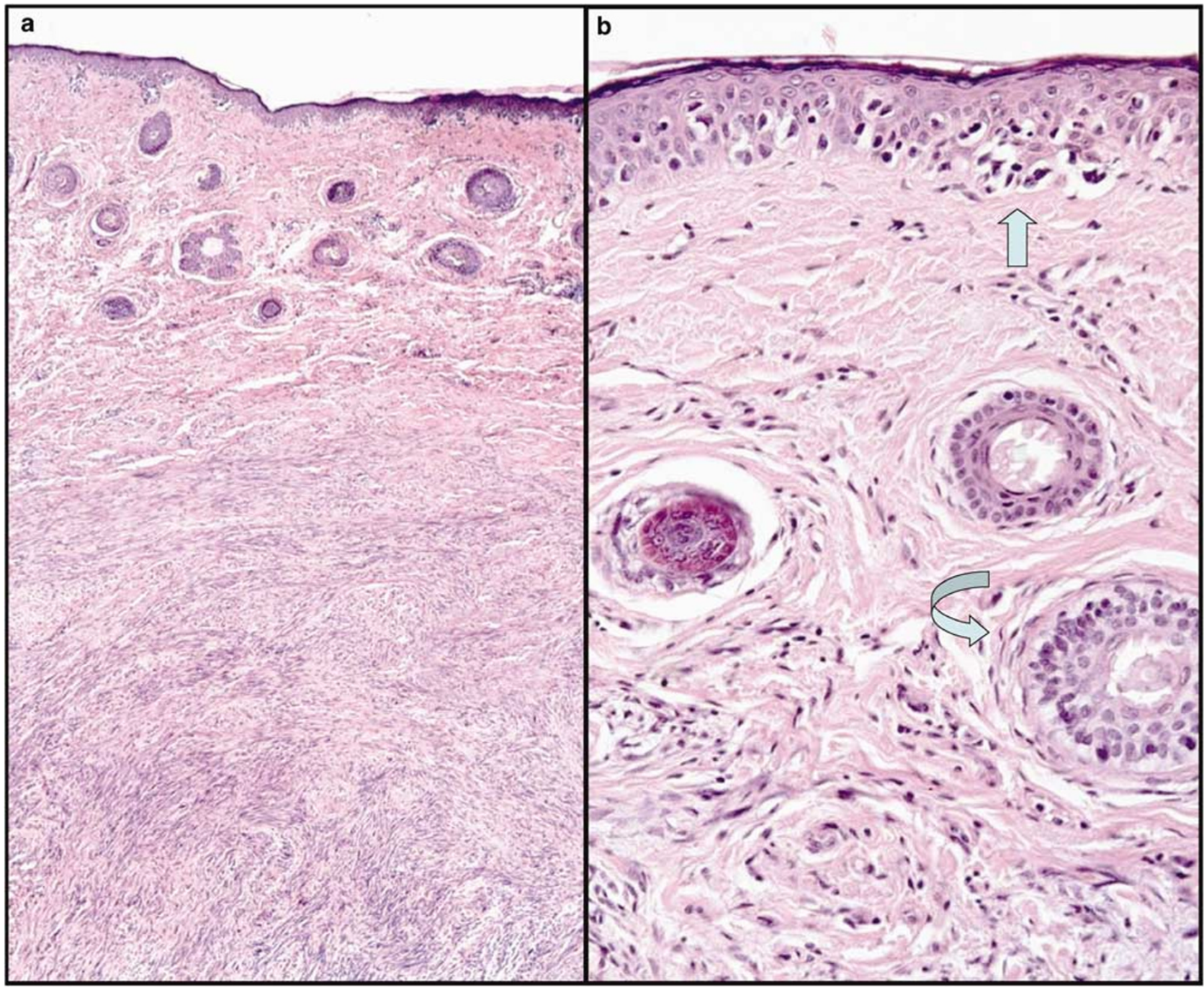

Figure 2 Desmoplastic melanoma: The dermis appears hypercellular in a diffuse, ill-defined fashion (a). There is lentiginous melanocytic hyperplasia and atypia (straight arrow) (b), an important criterion for desmoplastic melanomas arising in the setting of lentigo maligna, mucosal lentiginous or acral lentiginous melanoma. This finding is, unfortunately, seen in only roughly half of cases. There is invasion by atypical spindle cells into the adventitia of adnexal structures (curved arrow), another important criterion for this diagnosis which distinguishes desmoplastic melanoma from blue nevi and other melanocytoses that spare the adventitia.

The presence of a lymphocytic infiltrate in a sclerosing nevomelanocytic proliferation ought to prompt careful consideration of desmoplastic melanoma, in our view. Osteoid and bone formation may be seen, particularly in subungual desmoplastic melanomas. ${ }^{20}$

A recent study of 131 desmoplastic melanomas showed a pure desmoplastic morphology in 93 cases vs a mixed pattern in 39 cases, where the second component was nondesmoplastic and often epithelioid in character. ${ }^{21}$

\section{Differential Diagnosis}

Misdiagnosis at initial biopsy is common in our experience and that of others and may be the basis for inadequate initial local therapy that underlies the high rates of local recurrence of this neoplasm. ${ }^{4,22}$ Early lesions of desmoplastic melanoma may be difficult to distinguish from sclerosing nevi of spindle and/or epithelioid cell (ie, Spitz) type, sclerosing type A nevi, and sclerosing blue nevi. The latter lesions show a central zone of fibrosis with a well-circumscribed perimeter comprising typical blue nevus cells and macrophages that typically spare the adventitial dermis of the hair follicle. The desmoplastic Spitz nevus has an inverted wedgeshaped pattern, manifesting an admixture of spindle cells with delicate elongate nuclei and bizarre ganglion-like cells, the dual population of cell components that also typify the nonsclerotic Spitz nevus variant. The critical cell of the sclerosing type A nevus has a characteristic banal elongate or cigarshaped nuclear morphology with rounded or blunt nuclear contours and modest quantities of clear or 


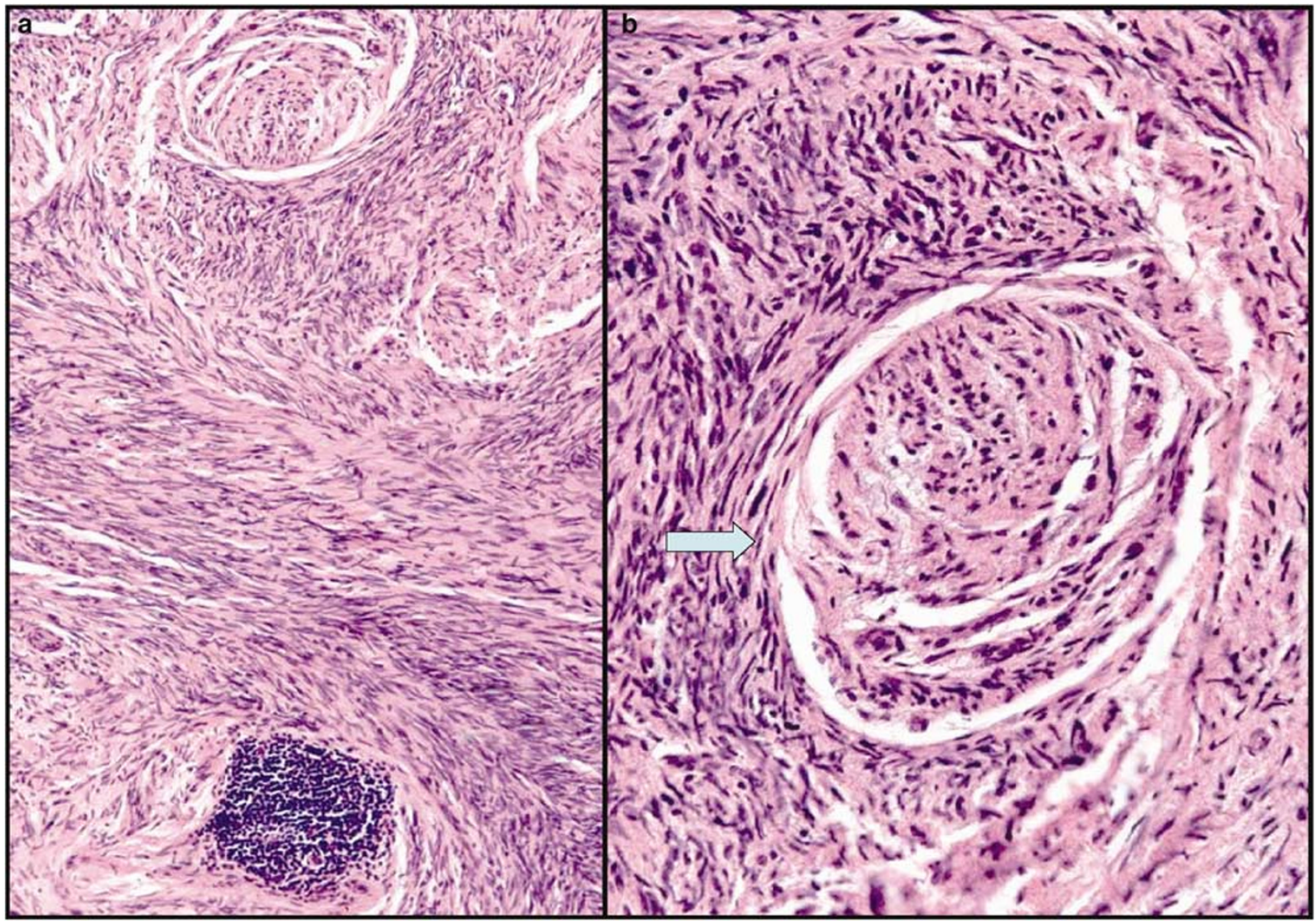

Figure 3 Desmoplastic melanoma: Nidi of chronic inflammation in any hypercellular, collagenized spindle cell lesion should merit extra scrutiny for other features of desmoplastic melanoma. These would include neurotropism (b-arrow).

lightly melanized cytoplasm. In contrast, early desmoplastic melanoma shows a haphazard, highly infiltrative pattern of growth in which large atypical hyperchromatic spindle cells deform the dermal architecture and invade the adventitial dermis of hair follicles. Neurotropism and foci of chronic inflammation typify desmoplastic melanoma ${ }^{2}$ but are usually absent in Spitz nevi. The nucleocytoplasmic ratios of desmoplastic melanoma are higher than in the cells of the Spitz nevus, the cytoplasms are more sparse, and usually, but not always, melanin pigment is absent in the cytosol of the melanocytes in desmoplastic melanoma. None of the aforementioned benign nevi manifest zones of mucinotic stromal change as is often present in the desmoplastic melanoma. ${ }^{2}$ Furthermore, most inverted type A nevi and most blue nevi lack a lentiginous junctional component, and although over one-half of Spitz nevi do have an intraepidermal melanocytic proliferation, this is more often nested than lentiginous in character and has a distinctive cytomorphology.

Metastatic melanoma may provoke a desmoplastic stromal response to generate a morphology that resembles the pattern of classical desmoplastic primary melanoma; neurotropism is said not to be seen in metastatic desmoplastic melanoma, however. $^{9}$

Nonmelanocytic neoplasms that enter the differential diagnosis include leiomyosarcoma, neurothekeoma and its cellular variant, spindle cell squamous cell carcinoma, and, of course, scars and dermatofibromata. ${ }^{22-24}$ Neurotropism may be seen in a number of benign and malignant neoplasms; as congenital and Spitz nevi may show this feature, it is certainly not pathognomonic of the malignant melanocytic phenotype. ${ }^{25}$ Neurotropism is also a feature of squamous cell carcinoma, basal cell carcinoma, keratoacanthoma, and adenoid cystic carcinoma, but these lesions should not pose a diagnostic dilemma when the appropriate immunohistochemical workup has been performed.

\section{Histogenesis}

The source of the collagen matrix in the desmoplastic melanoma is a subject of considerable controversy. According to one hypothesis, that the tumor cells evoke a host response characterized by a 


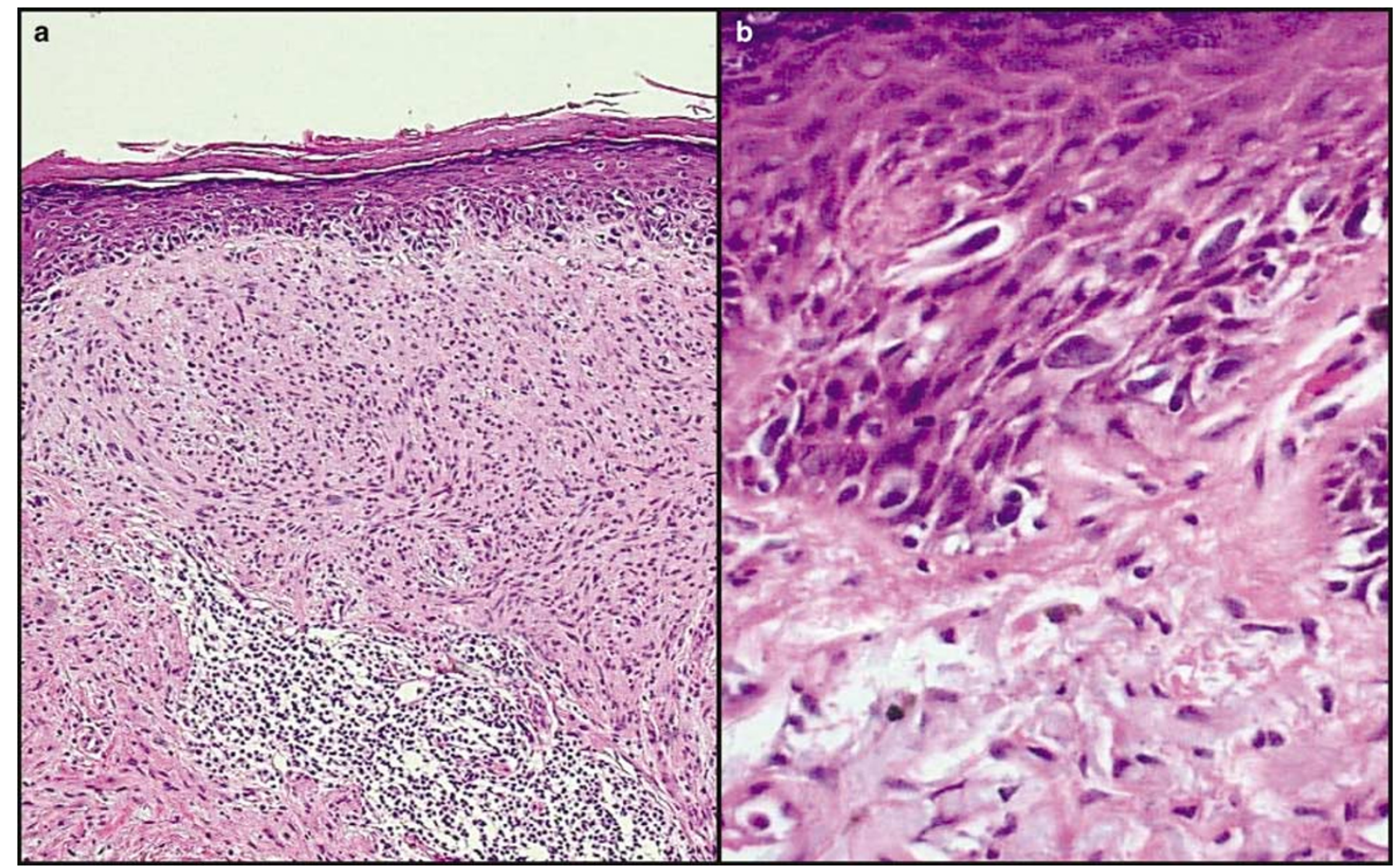

Figure 4 Desmoplastic melanoma: In addition to lentiginous melanoma in situ (a and b) this diffusely cellular dermis is heavily infiltrated by small lymphoid forms (a). Note dermal solar elastosis in this lesion which has arisen in the setting of lentigo maligna (b).

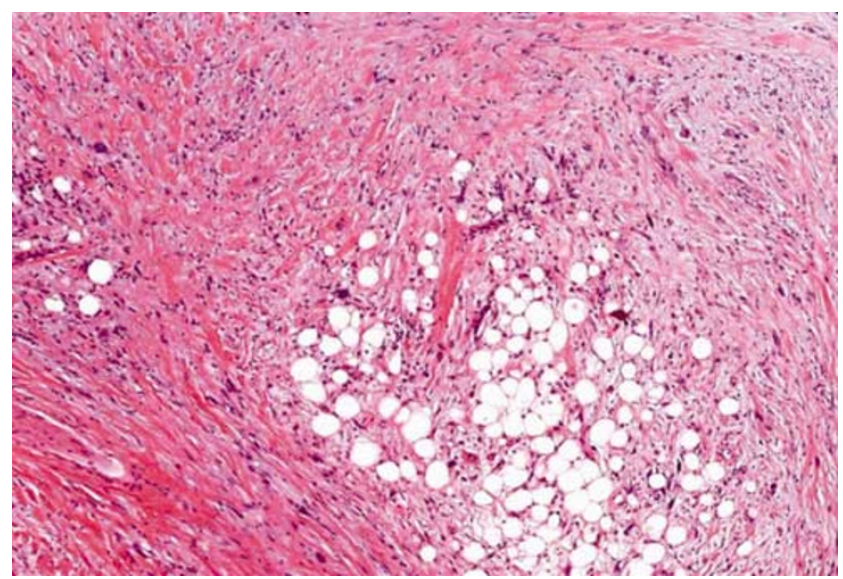

Figure 5 Desmoplastic melanoma: Hyperchromatic spindle cell forms extend between and around the fat lobules that are associated with fatty atrophy in this tumor which extends into the subcutaneous fascia.

proliferation of fibroblasts, the collagen production is of fibroblastic origin. The alternative hypothesis is that the tumor cells are dedifferentiated neoplastic melanocytes that function as facultative fibroblasts. ${ }^{26}$ Supportive of the latter hypothesis are ultrastructural studies showing fibroblastic qualities in the neoplastic cells ${ }^{11}$ and macular desmosomes between adjoining neoplastic cells, held to be

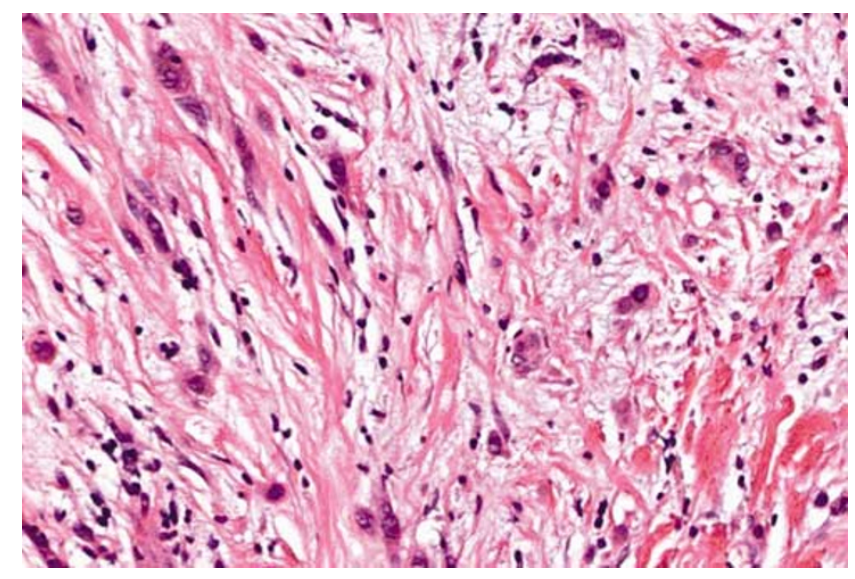

Figure 6 Desmoplastic melanoma: Note the hyperchromatic fusiform neoplastic cells, the abundant quantity of mature eosinophilic collagen fiber deposition and stromal mucinosis which is pronounced in this example. Lymphocytes diffusely percolate the dermis.

evidence that the tumor populace constitutes a modified or dedifferentiated melanocyte with fibroblastic attributes. ${ }^{27,28}$ Macular desmosomes are a characteristic feature of melanoma and likely account for the tendency for nesting of dermal melanocytes seen in a minority of desmoplastic melanomas. The concomitant fibroblast-like features identified in the tumor cells include the presence of 
dilated rough endoplasmic reticulum. ${ }^{27,28}$ The tumor cells of desmoplastic melanoma decorate with antibodies to S100 protein in an almost ubiquitous fashion, ${ }^{6}$ with antibodies to neuron-specific enolase in $40-96 \%$ of cases, ${ }^{6,17}$ and with HMB-45 in roughly $20 \%$ of $\operatorname{cases}^{6}$ (Figure 7). Typically, HMB-45 either gives negative results ${ }^{29}$ or shows differential staining patterns in which tumor cells are weakly positive superficially, with negative results in the deep portions of the tumor. ${ }^{30}$ As previously mentioned, this staining pattern is different from that observed in the blue nevus with atypia seen in elderly patients. Similarly, sclerosing Spitz nevi tend to show high HMB-45 expression superficially, which tapers off to negativity in the lesional base; the finding of an HMB-45-negative sclerosing nevomelanocytic proliferation ought to prompt careful scrutiny for criteria of desmoplastic melanoma. Longacre et $a l^{31}$ established that lesional melanocytes decorated with S100 protein in $94 \%$ of 32 studied cases of desmoplastic and spindle cell melanoma, of which two S100-positive cases showed decoration in fewer than $5 \%$ of the critical cells. Using a two-color system, they demonstrated that $32 \%$ of cases contained a significant number of smooth muscle actin-positive cells, interpreted by them as representing myofibroblasts, admixed with the neoplastic spindled melanocytes and representing the putative source of the desmoplasia in these neoplasms. ${ }^{31}$ This study would support the first construction concerning the histogenesis of desmoplastic melanoma, that is, that a biphasic populace is present and that the melanocytes and the collagen-producing myofibroblastic cells are two distinct and phenotypically separable populations.

The tendency for desmoplastic melanoma to manifest neurotropism and stromal collagenization can be explained at the molecular level by gene expression profiling that shows activation of genes encoding for neurotrophic factors and for extracellular matric elaboration, ${ }^{32}$ expressed at the protein level in fixed tissues by immunohistochemical assay

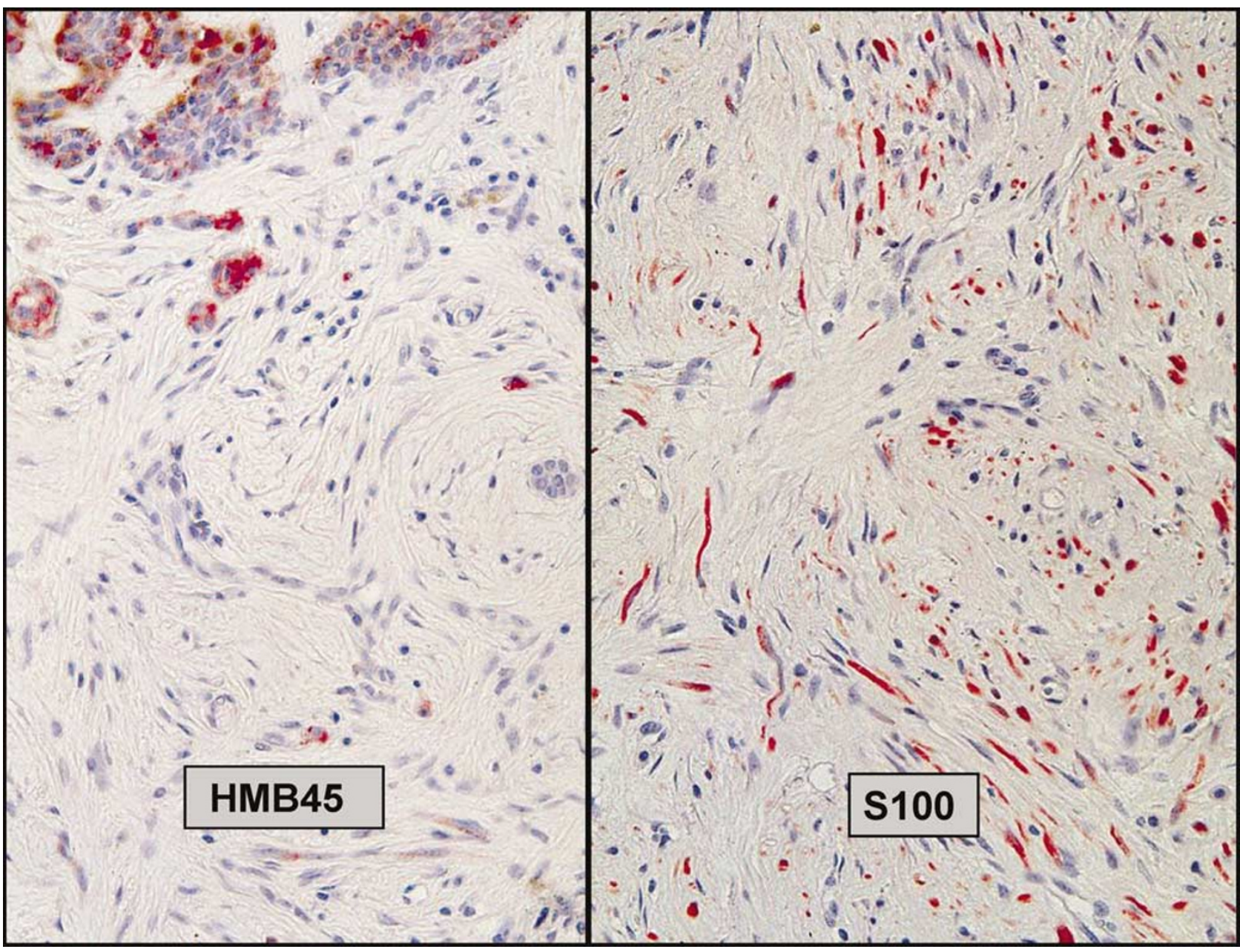

Figure 7 Desmoplastic melanoma: Immunohistochemical profile. HMB 45 and other markers of melanocyte lineage-specific differentiation are either negative in desmoplastic melanoma or focally positive and then only in the more superficial aspects of the neoplasm (left panel). Immunohistochemical studies for S100 protein, in contrast, diffusely decorate the neoplasm in the great majority of cases (right panel). 
for p75 nerve growth factor receptor, ${ }^{33}$ basic fibroblast growth factor $(\mathrm{b}-\mathrm{FGF})^{34}$ and the fibroblastic markers CD90 and CD13. ${ }^{35}$ The expression of genes for melanocytic differentiation was reduced in desmoplastic melanoma as compared to conventional melanoma; the reduced melanocyte differentiation gene expression has its counterpart at the tissue level by virtue of absent expression of melanocyte lineage-specific markers such as HMB45 and Melan-A, ${ }^{6}$ tyrosinase and D5, an antibody to microphthalmia transcription factor (Mit-f). ${ }^{36,37}$ More recently, a similar lack of immunoreactivity has been described with the novel monoclonal antibody PNL2. ${ }^{38}$

\section{Therapy}

Since the lesions are often amelanotic, and so mimic scars and basal cell and squamous cell carcinomas clinically, initial biopsy may be delayed, ${ }^{39}$ compounding the problem of histologic misdiagnosis mentioned above and so delaying proper surgical therapy. ${ }^{4,22}$ Deep excision to encompass fascia, where possible, is often advised owing to the deeply invasive nature of the neurotropic component. ${ }^{39}$ Great care must be taken to ensure that there is no evidence of perineural infiltration in the margins, the commonest cause of recurrence. Survivorship at 5 years approaches $75 \%$, and, in thin lesions $<2 \mathrm{~mm}$ in thickness, $90 \%{ }^{39}$ It has been suggested that those desmoplastic melanomas having foci of conventional vertical growth phase melanoma manifest a significantly worse prognosis, with regional lymph node metastases in $10 \%$ of cases as opposed to only $1 \%$ of patients with pure desmoplastic melanoma. ${ }^{21}$ Disease-specific 5-year mortality in one study was $11 \%$ for pure desmoplastic vertical growth phase tumors, vs 31\% for those neoplasms having the aforementioned hybrid morphology. ${ }^{21}$ There is little doubt that desmoplastic melanoma manifests up to a three-fold greater thickness at presentation but nonetheless has better survivorship than conventional melanomas of similar thickness. ${ }^{21}$

\section{Nevoid malignant melanoma}

\section{Introduction and Clinical Features}

The term nevoid melanoma was first proposed by Schmoeckel et $a l^{40}$ to describe a heterogeneous group of lesions showing histologic features closely recapitulating a benign nevus including a symmetrical, dome-shaped or verrucous and papillomatous silhouette and a cell populace manifesting apparent maturation of cells with descent in the dermis. ${ }^{40-45}$ The clinical setting in our experience is that of a tan nodule typically greater than $1 \mathrm{~cm}$ in size on the trunk or proximal limbs of a young adult. Our experience is thus similar to that of Blessing et $a l^{43}$ but is at variance with that of Kossard and
Wilkinson. ${ }^{46}$ This is, fortunately for pathologists, a rare form of malignant melanoma comprising less than $1 \%$ of all lesions seen in consultation. The lesions behave like invasive melanoma including in the context of local recurrence and metastatic disease. $^{40,45}$ However, in our opinion, many of the cases so designated were, in fact, small epithelioid melanomas in which the pleomorphic confluent growth and high mitotic rate distinguished the lesions from nevoid melanoma. Previous reports describing a similar entity under a different nomenclature antedated the report of Schmoekel et al; ${ }^{41,42}$ Levene described such deceptively bland-appearing lesions as 'verrucous pseudonevoid melanoma,' and, indeed, the lesions clinically resemble benign nevi. In a series of 33 cases, 15 patients developed metastatic disease and eight died of disseminated melanoma. ${ }^{40}$ In the series of 15 patients reported by McNutt et al, ${ }^{47}$ recurrent disease was observed in three patients; local nodal metastases developed in three patients, cutaneous metastatic disease in three patients, and disseminated disease in one patient, a 32-year-old male who succumbed to his cancer. There was a 2:1 male predominance and the average age was 43 years. In the series by Wong et $a l,{ }^{45}$ regional metastases developed in one patient, local recurrence in three, and three were reported to be alive and well with no evidence of disease after excision. The average age at presentation in the latter series was 40 years; there was a similar slight male predominance. In a series of 20 patients with nevoid melanoma, the mortality and metastasis rate at 3 years was $37.5 \% .{ }^{48}$ These lesions are not to be confused with minimal-deviation melanoma, which is considered a borderline tumor whose biological behavior is difficult to predict on the basis of the histology of the primary lesion.

\section{Histology}

Low-power architectural examination reveals either a verrucoid (Figures 8-10) or a dome-shaped pattern (Figure 11). In a series of 20 patients with nevoid melanoma, 13 had dome-shaped surface contours while seven were verrucous in character. ${ }^{48}$ There is a circumscribed subjacent proliferation of mitotically active melanocytes (Figure 10) that extends to lie in direct apposition to either a smooth, papillomatous or verrucous epidermis. The lesions manifest sharp lateral circumscription. ${ }^{45,47}$ With respect to the intraepidermal component, prominent pagetoid infiltration is notably absent. Junctional activity is uncommon but can be observed in some cases of verrucoid forms of nevoid melanoma. The superficial dermal component is composed of nests of epithelioid-appearing melanocytes (Figure 12); a discernible spindle-cell component is not identified. In the verrucous variant, the superficial nests can be quite large with confluence. There may be a gradual diminution in cell size toward the base. ${ }^{44,47}$ 
In addition, the cells are arranged in smaller units including short cords, small nests, ${ }^{44}$ and a singlecell dispersion ${ }^{47}$ (Figure 13). The base is not well demarcated. The dermal component typically extends into the superficial reticular dermis for a depth of anywhere from 0.67 to $1.2 \mathrm{~mm}$ from the epidermal surface. ${ }^{44}$ Although the cells at the base

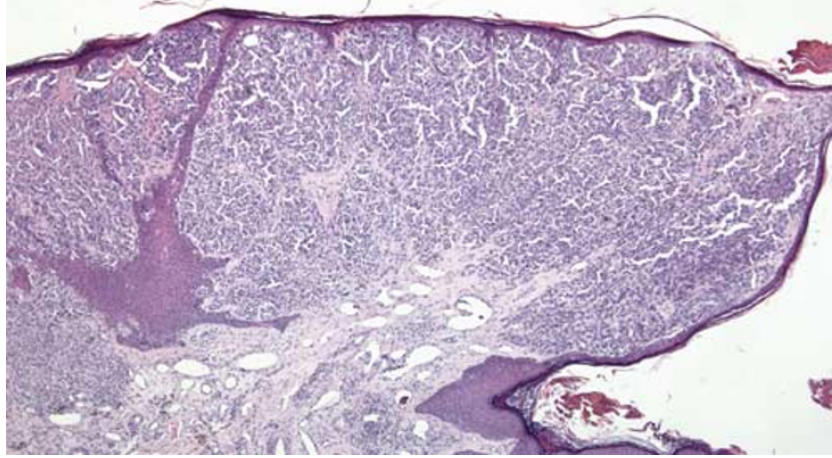

Figure 8 Nevoid melanoma: Verrucous variant. This verrucous nevoid melanoma shows a polypoid surface contour with confluent and nodular growth of neoplastic melanocytes causing an asymmetric expansile dermal population. are smaller, they show atypical features including conspicuous nucleolation, nuclear membrane irregularity, hyperchromasia, increased nuclear-to-cytoplasmic ratios, and mitotic activity, all of which are

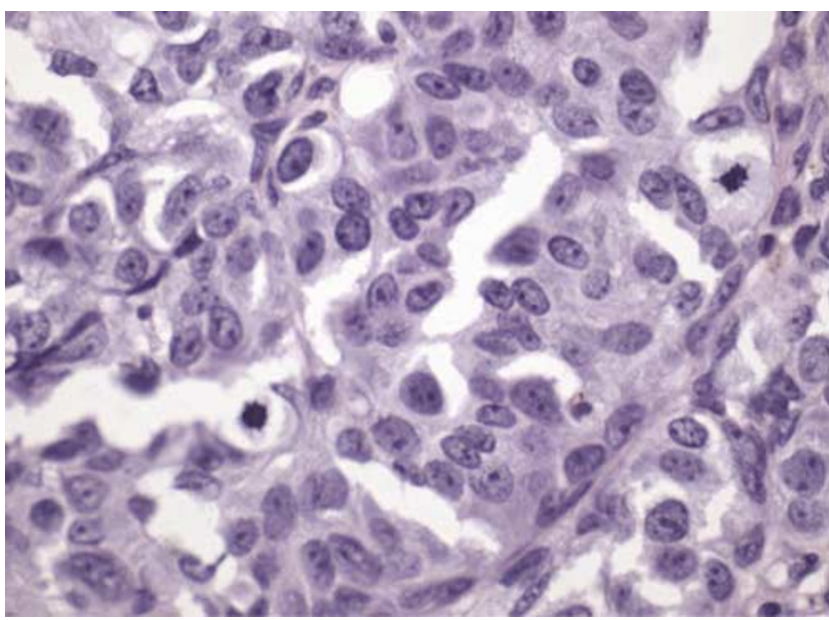

Figure 10 Nevoid melanoma: Two mitotic figures are demonstrated in this single $\times 60$ high dry objective magnification image. Note that the neoplastic cells are monotonous, manifesting prominent nucleoli and occasion bean-shaped grooved nuclei.

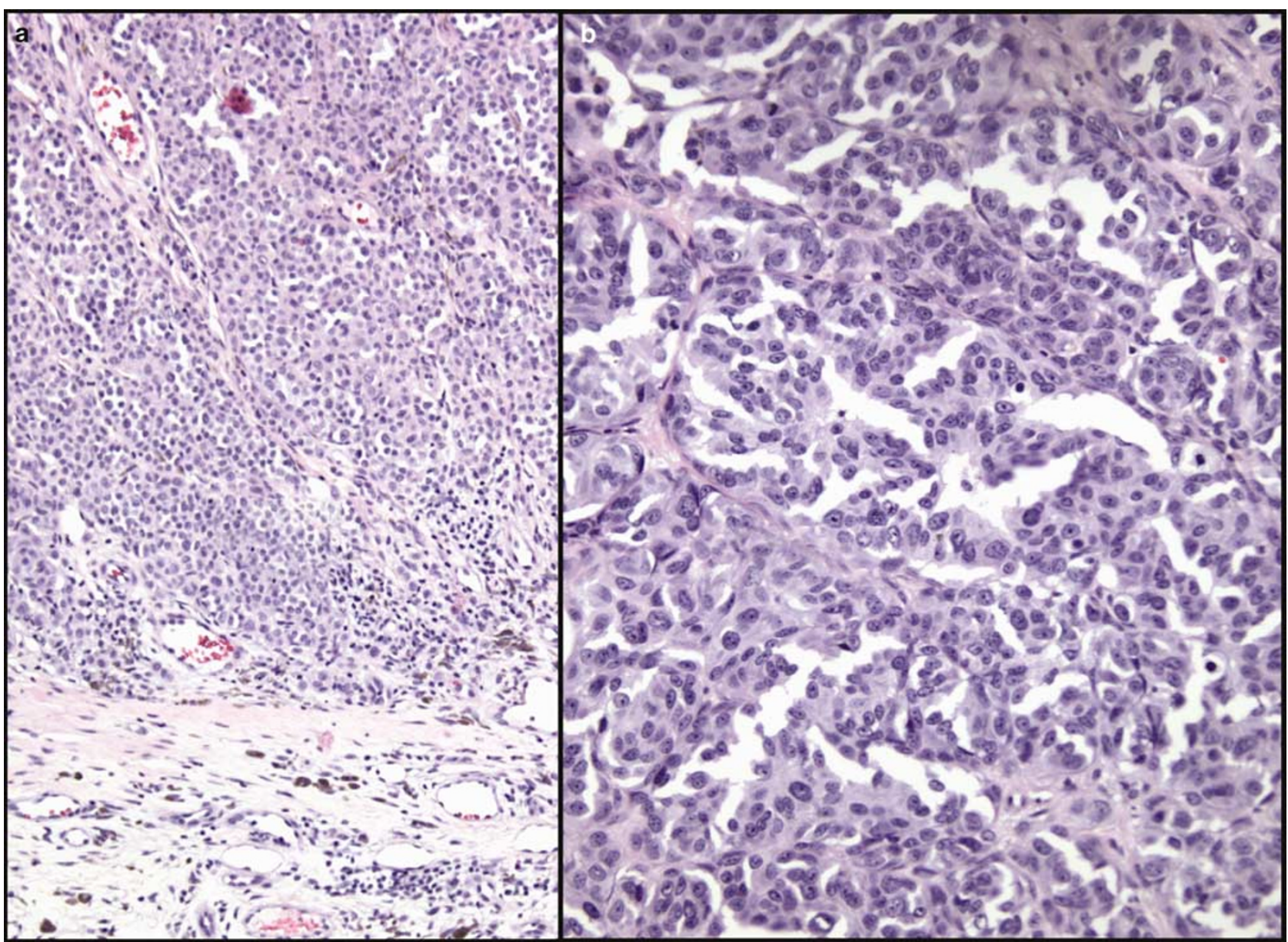

Figure 9 Nevoid melanoma: The tumor cells form confluent expansile nodules and sheets (a) of monotonous melanocytes (b). 


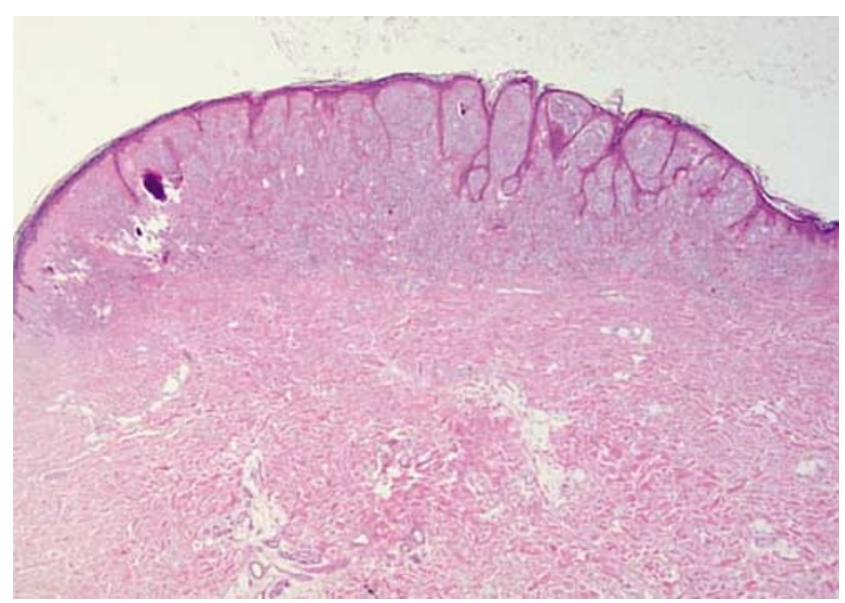

Figure 11 Nevoid melanoma: Smooth contoured variant. The upper dermis is diffusely replaced by neoplastic melanocytes in this example of a nevoid melanoma which has generated a smooth surface contour.

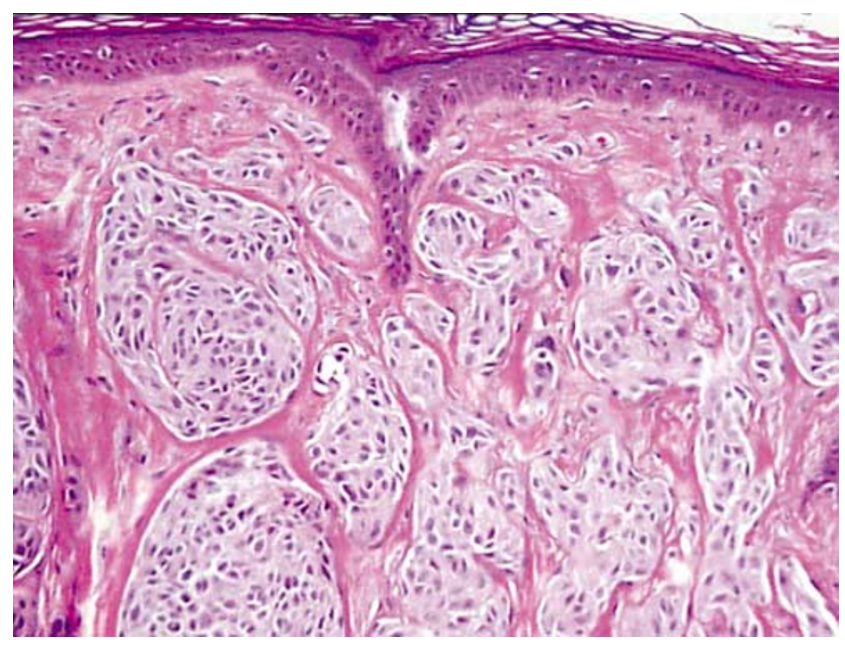

Figure 12 Nevoid melanoma: There are expansile nodules deforming the papillary dermis.

unusual in the banal common acquired nevus (Figures 14 and 15). Features that allow easy recognition of the process as malignant melanoma, such as a pushing border, high mitotic activity, and striking pleomorphism, are usually absent, which compounds the risk of misdiagnosis of such lesions as benign dermal nevi. Foci consistent with a residual dermal nevus are not usually present. Lymphatic invasion can be observed and may be a sign of more aggressive behavior. ${ }^{44}$

\section{Differential Diagnosis}

The differential diagnosis of such lesions includes minimal-deviation melanoma, nodular melanoma, and melanoma arising in a dermal nevus. ${ }^{49,50}$ With respect to the first two considerations, the pattern of growth is not nevoid but rather is an expansile nodule distorting and effacing the dermal architec-

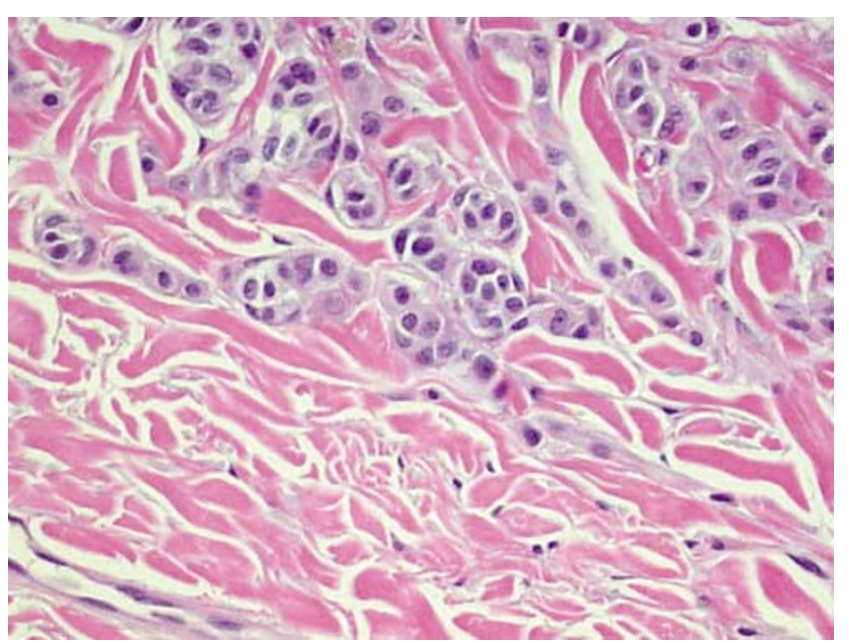

Figure 13 Nevoid melanoma: At the base, the neoplastic cells manifest little or no maturation in this example; rather, the tumor cells show prominent nucleoli and large nuclei. Pseudomaturation may be seen due to presumptive compression of neoplastic cells by the collagen table, a deceptive finding in nevoid melanoma that mimics closely a benign melanocytic nevus.

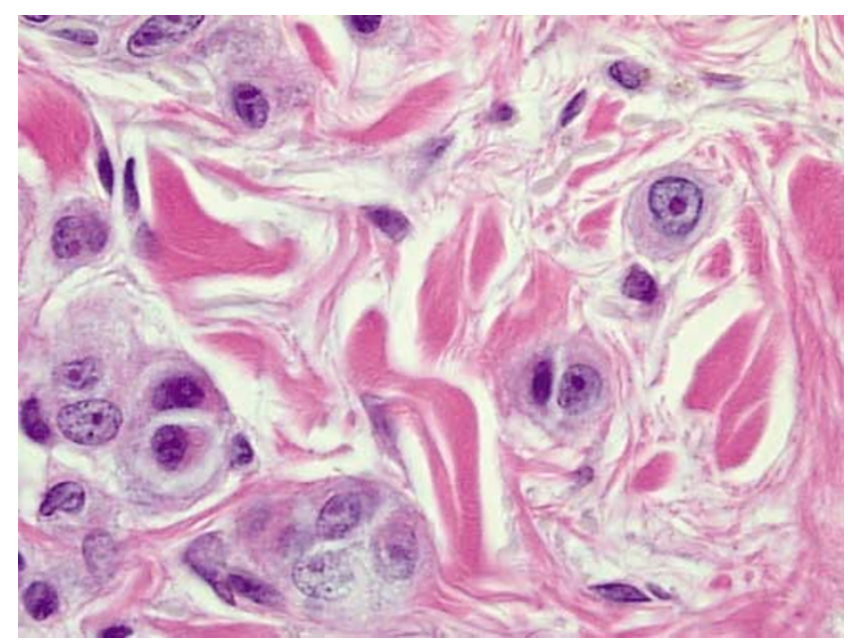

Figure 14 This oil immersion ( $\times 1000$ magnification) image shows the fully transformed malignant cytomorphology of nevoid melanoma. In particular, the chromatinic rims of the neoplastic melanocytes are irregularly thickened, the nucleoli are prominent and the chromatin is spiculated.

ture. Other features such as high-grade nuclear atypia and intraepidermal melanocytic atypia consistent with melanoma in situ are further differentiating points of nodular melanoma from nevoid melanoma. In minimal-deviation melanoma, the disposition of the cells within the dermis should allow distinction..$^{49,50}$ The expansile growth pattern displaces surrounding structures, and there are frequently remnants of the pre-existing benign nevus, be it a Spitz nevus, a congenital nevus, a common acquired nevus, or a pigmented spindle cell nevus. The minimal-deviation melanoma is equivalent to at least a level III melanoma with respect to the extent of dermal invasion. ${ }^{51}$ The 


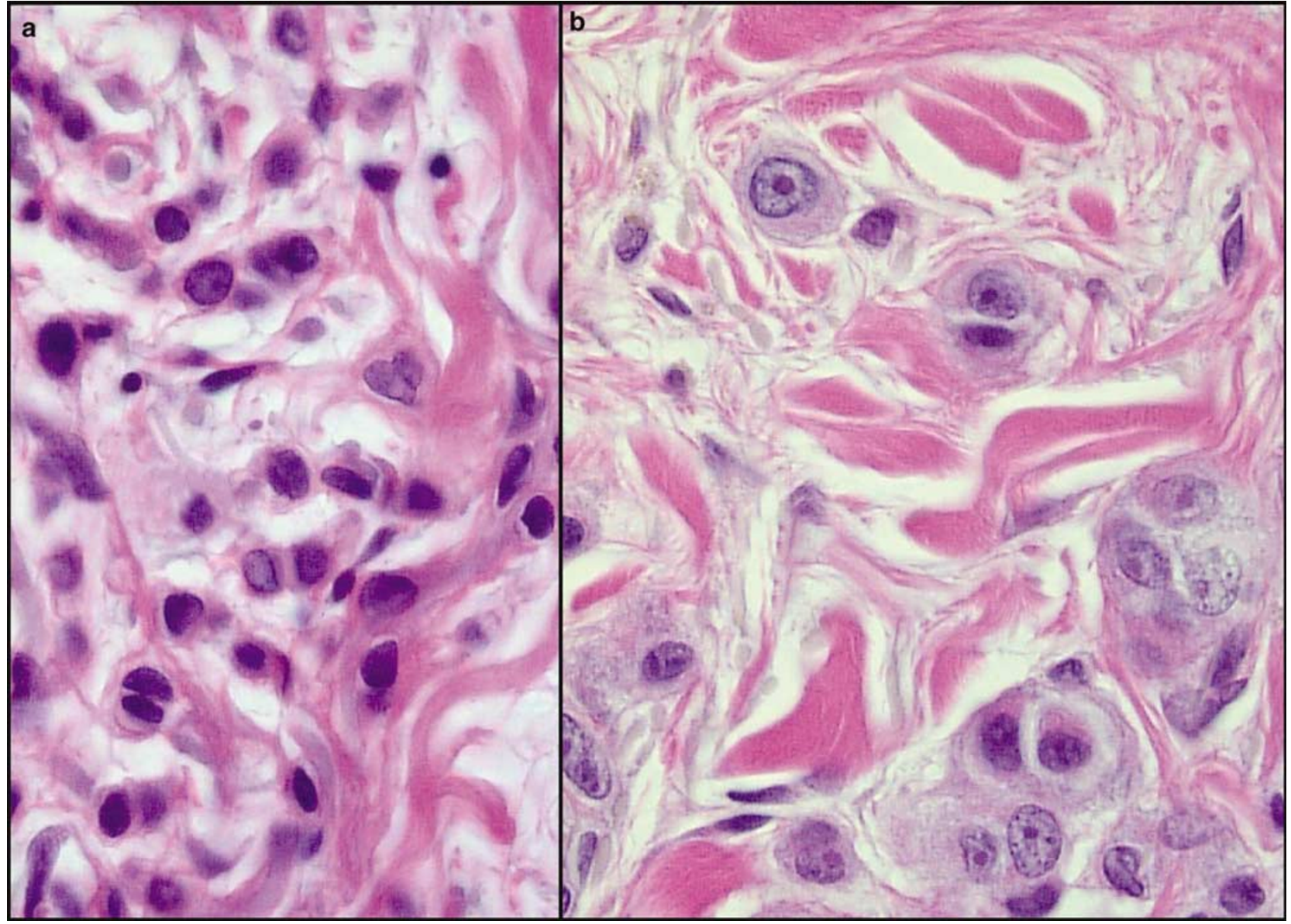

Figure 15 Nevoid melanoma: High-power morphology. The contrast between banal nevomelanocytes at the base of a benign intradermal nevus (a) with the neoplastic fully transformed melanocytes of nevoid melanoma (b) is evident when seen at identical high power magnification.

cells are relatively monotypic, manifesting mild to moderate atypia in contrast to the more fully evolved atypia seen in nevoid melanoma. The latter manifests more hyperchromatic nuclei and higher nuclear-to-cytoplasmic ratios. Mitoses are typically more scarce in minimal-deviation melanoma than in nevoid melanoma. ${ }^{49-52}$ In melanomas arising in dermal nevi, by definition, there is a residual nevus, a feature not typical of nevoid melanoma. In addition, there is extension into the deep reticular dermis and fat accounting for depths greater than those reported in nevoid melanoma. ${ }^{53}$

There are ancillary studies that can be used to further differentiate nevoid melanoma from either dermal nevi or more common forms of melanoma. The average number of nucleolar organizing regions and their nuclear area and perimeter are significantly smaller for nevoid melanoma compared to those of superficial spreading melanoma and significantly greater than those of banal dermal nevi. Digital image analysis has shown that nuclear area in nevoid melanoma is similar to that of benign nevi; however, it is significantly less than that of convention melanoma. ${ }^{54}$ The differential superficial expression of HMB-45 and Ki-67 which characterizes benign nevomelanocytic proliferations is characteristically lost in nevoid melanoma (Figures 16 and 17).

\section{Minimal-deviation melanoma}

\section{Introduction and Clinical Features}

The concept of minimal-deviation melanoma as introduced by Richard Reed is not one that is universally accepted. We feel that minimal-deviation melanoma does, indeed, represent a distinct clinicopathologic entity. All such tumors share an architectural growth pattern that simulates vertical growth phase melanoma but lack the cytologic features diagnostic of malignant transformation. ${ }^{19,52}$ The prognosis of minimal-deviation melanoma is uncertain, but it has been imputed in limited series to be better when compared with other melanomas at a similar depth and level of invasion..$^{55}$

The minimal-deviation melanoma presents either as a nodule or a plaque that varies from fleshcolored to dark brown or blue-black, most often 


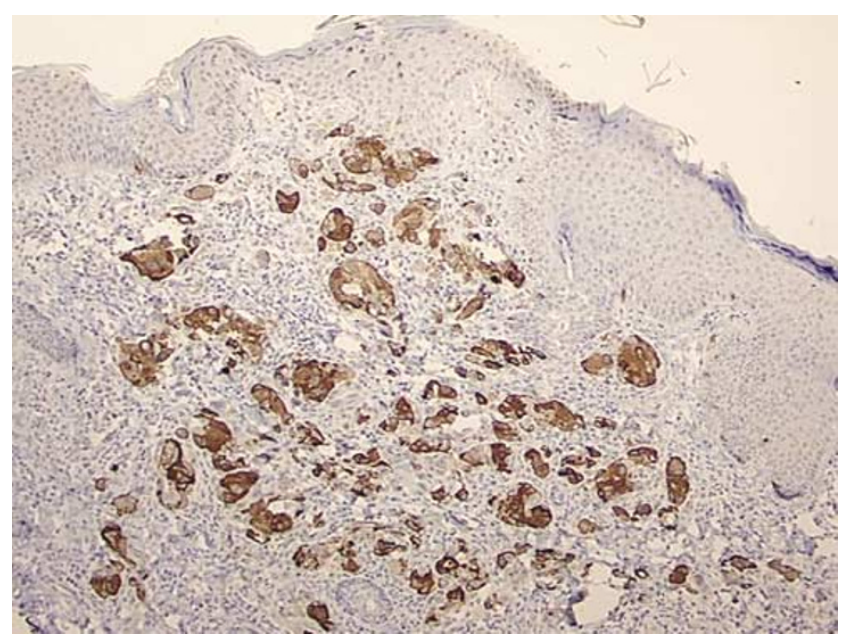

Figure 16 Nevoid melanoma: Loss of differential HMB 45 expression. Most nevi show progressive diminution of HMB 45 and Melan-A expression in the deeper dermis. Note that this nevoid melanoma shows diffuse expression of HMB 45 in the neoplastic population.

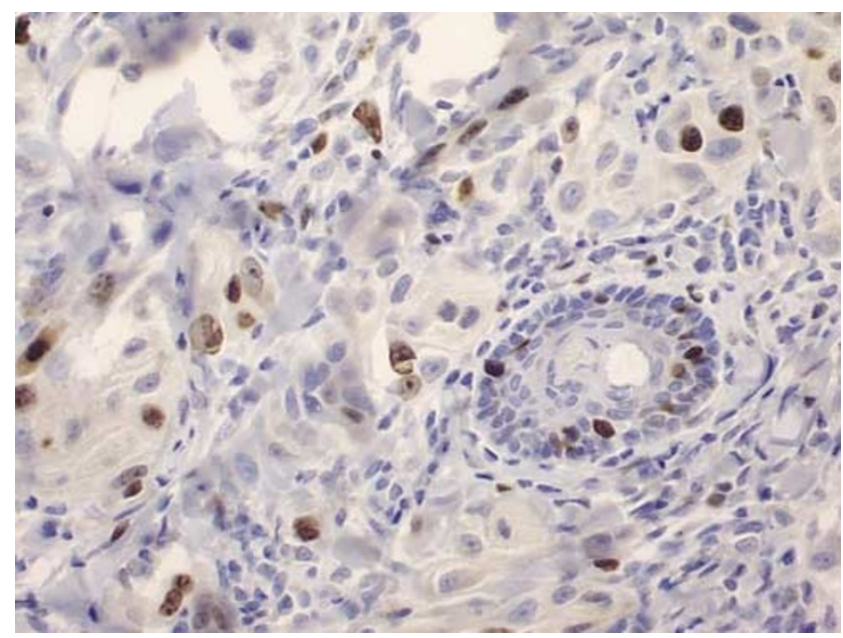

Figure 17 Nevoid melanoma: Ki-67 decoration. In nevoid melanoma, Ki-67 expression is higher than that seen in benign, common acquired, and Spitz's nevi where less than $10 \%$ and often less than $5 \%$ of the critical cells decorate with this nuclear marker of proliferation. In nevoid melanoma, greater than $10 \%$, and often greater than $20 \%$ of neoplastic cells decorate. Furthermore, there is no differential decoration pattern. That is, the neoplastic melanocytes diffusely express Ki-67 in a patternless fashion.

ranging in size from 0.5 to $1.0 \mathrm{~cm}$, and is characteristically located on the trunk. Young adults in the third and fourth decades of life are most frequently affected. Often demonstrated histologically is a preexisting acquired nevus or a congenital nevus. When present in a congenital nevus, the minimal-deviation melanoma may manifest as a subcutaneous nodule; such a nodule is commonly misdiagnosed as an epidermal cyst. The histopathology of the prototypic minimal-deviation melanoma is discussed below, followed by a consideration of the entity known as minimal-deviation melanoma of

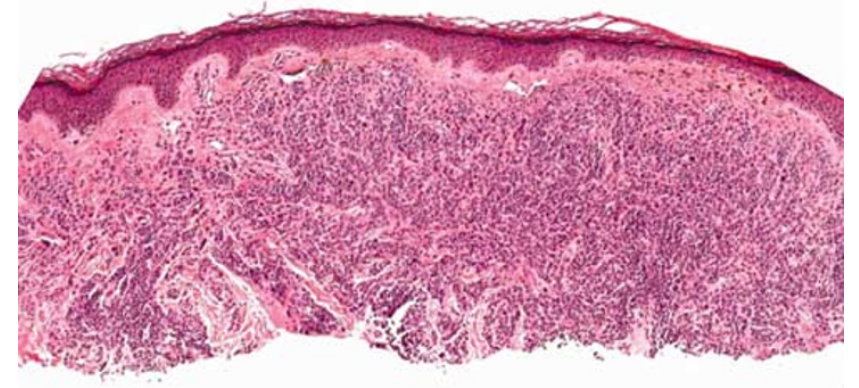

Figure 18 Minimal-deviation melanoma: Low-power architecture. The minimal-deviation melanoma manifests either a diffuse replacement of papillary and reticular dermal collagen or an asymmetric, expansile nodule of rather monotonous cells.

Spitzian type. The mean age was 27 years in a recent study from Irvine, California. ${ }^{56}$ The behavior of such lesions is unpredictable. Although in most cases the behavior appears indolent, ${ }^{56}$ nonetheless aggressive behavior as defined by metastatic disease has been reported ${ }^{57,58}$ and has certainly been encountered in our experience. Reed himself has suggested that minimal-deivation melanoma of less than $1.5 \mathrm{~mm}$ in thickness might better be classified as a 'melanocytic neoplasm of indeterminate malignant potential'. ${ }^{59}$

\section{Histology}

Minimal-deviation melanoma is characterized by an expansile nodule either confined to the papillary dermis (for which the appellation 'borderline melanoma' was applied by Richard Reed) or permeative of the reticular dermis (minimal-deviation melanoma), hence resembling at scanning magnification fully evolved level III or IV vertical growth phase malignant melanoma (Figure 18). The minimaldeviation melanoma averages $3.40 \mathrm{~mm}$ in thickness, whereas borderline melanomas average $1.24 \mathrm{~mm}$ in thickness. There is usually no infiltration of the subcutaneous fat except in those minimal-deviation melanomas that arise in congenital nevi or in the Spitzian variant of minimal-deviation melanoma. Perineural invasion can be observed. Although the prototypic low-power architecture is one of an expansile nodule, one report describes a spindle cell form of minimal-deviation melanoma that assumed a diffusely infiltrative pattern within the dermis. ${ }^{58}$ Mitoses are infrequently observed, and necrosis is absent. Inflammation with desmoplasia may be noted but is usually absent. ${ }^{49,51,60}$ 
The nodules of minimal-deviation melanoma and borderline melanoma are composed of a relatively uniform population of moderately atypical-appearing nevus-like cells; such cells may resemble type A, $\mathrm{B}$, or $\mathrm{C}$ nevomelanocytes or have a predominantly spindle cell morphology resembling a pigmented spindle cell nevus. ${ }^{23,55,58,61}$ Within a given lesion, there is monotypism of cell type (Figure 19). The usual prognostic variables that apply to invasive melanoma are not assigned to a lesion of minimaldeviation melanoma as its biological behavior cannot be predicted in the same fashion as the more aggressive conventional malignant melanoma. The cells of minimal-deviation melanoma resemble nevus cells but exhibit moderately enlarged nuclei, irregular chromatin distribution, and increased nuclear-to-cytoplasmic ratios relative to benign nevus cells (Figure 20). Conspicuous nucleoli are identified. There is no apparent maturation either with respect to diminution in cell or nest size. However, the nests and/or fascicles are closely apposed with narrow bands of intervening collagenous matrix, and are irregular in size, outline, and aggregation. Mitotic activity is usually quite low; up to six mitoses per 100 high-power fields are observed. Corresponding studies of Ki-67 labeling show a proliferation index greater than that of Spitz

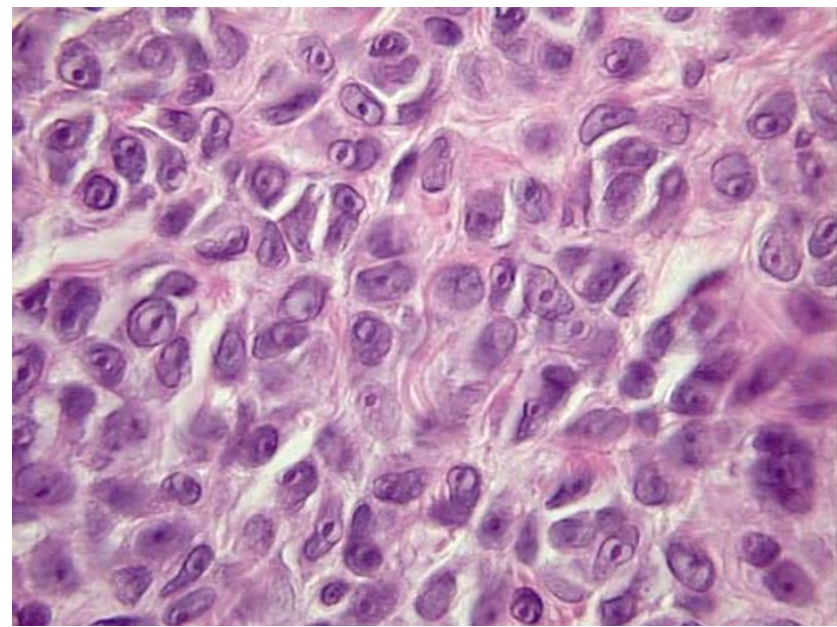

Figure 19 Minimal-deviation melanoma: High power microscopy. In this oil immersion $(1000 \times$ objective magnification) micrograph, the cells are monotonous, show prominent nucleoli and, frequently, irregular nuclear contours.

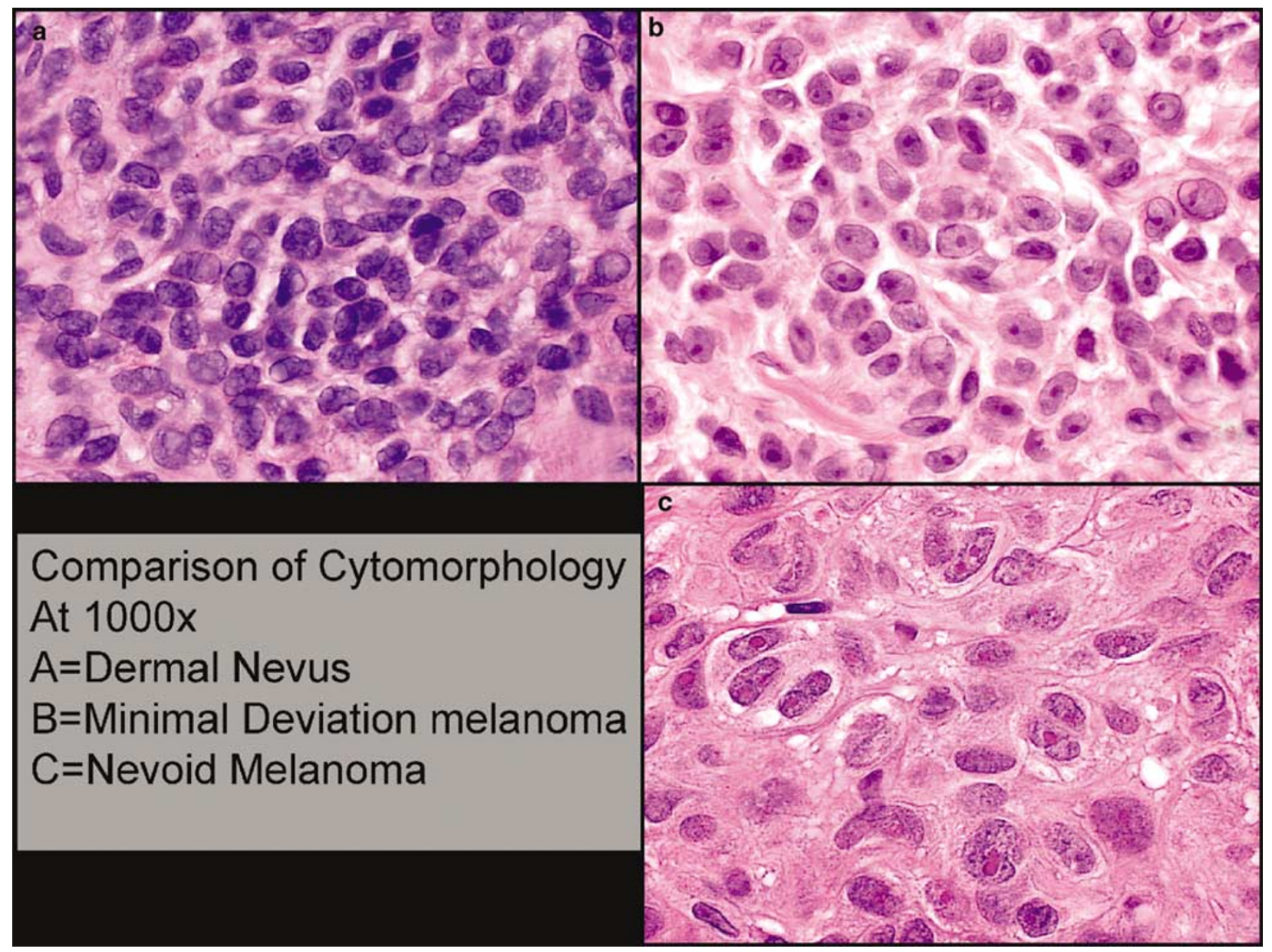

Figure 20 This illustration demonstrates the comparative morphology of the melanocytes at $1000 \times$ magnification in a banal intradermal nevus (a), a minimal-deviation melanoma (b) and a nevoid melanoma (c). As can be easily appreciated, the minimal-deviation melanoma manifests a particularly treacherous cytology and also, at least in the hands of some observers, has a lower risk of metastasis than nevoid and other more conventional vertical growth phase melanomas of epithelioid type. 
or common compound nevi but less than that of superficial spreading melanoma. ${ }^{62}$

The distinction of a minimal-deviation melanoma arising in a congenital nevus from the proliferation nodule of a congenital nevus may be difficult. There is little difference architecturally, as both manifest a nodular pattern of growth that results in distortion of the dermal silhouette. However, in the proliferation nodule the cells are cytologically bland with inconspicuous nucleoli and merge with the background nevus cell population. Collagen surrounds the individual nevomelanocytes within proliferation nodules, whereas tumor cells in minimal-deviation melanoma are not surrounded by collagen or basement membrane material. This likely relates to certain biological properties of vertical growth phase melanoma, specifically, the expression of transmembrane metalloproteinases which digest basement membrane material and facilitate the growth and spread of tumor. In minimal-deviation melanoma cellular atypia and rare mitoses are seen. The cells have a cytomorphology disparate from the remainder of the lesion. Mitoses are uncommon in both the proliferation nodule and the minimal-deviation melanoma, but, because mitoses can be seen in either, their presence is not a distinguishing criterion.

\section{Equine/animal-type melanoma in humans: malignant melanoma with prominent pigment synthesis}

\section{Introduction}

The existence in horses of skin neoplasms comprising nodules of heavily melanized cells has been recognized for centuries and is termed equine melanotic disease. ${ }^{63-65}$ These common neoplasms classically develop in old gray horses and are also described in nonequine animal models such as those induced via cutaneous application of topical carcinogens. ${ }^{66-69}$ The similarities between these lesions and a similar process in humans were first recognized by Darier in $1925 .^{70}$ As only a few human cases are described, the biological behavior of these heavily pigmented 'animal-type' melanomas is unclear. ${ }^{71}$ In one series, patients seemed to manifest a long indolent phase, ${ }^{72}$ although in our hands two of six patients developed metastases and one died of disease. ${ }^{71}$ There is one case report where metastasis to a regional lymph node occurred without widespread dissemination, another case report describing a local cutaneous metastasis 1 year after excision, ${ }^{65}$ and a third case report of a patient who developed widespread metastatic disease. ${ }^{73}$

Animal-type melanoma manifests a common theme, namely, a tumorous proliferation of melanocytes with striking pigment synthesis. The differential diagnosis encompasses benign cellular pigment-synthesizing melanocytic tumors, but there is sufficient distinctiveness to the histomorphology and to the biological behavior to preclude other diagnoses such as cellular blue nevus or deeppenetrating nevus.

\section{Clinical Features}

The lesions present as blue-black plaques or nodules averaging $1 \mathrm{~cm}$ in diameter, but with some lesions measuring several centimeters, without a predilection for site or sex. In our own series, four of the patients were in the first or second decades of life, suggesting an incidence skewed to a younger population. There was no association with familial dysplastic nevus syndrome, sun exposure, or family history of melanoma. ${ }^{71}$ Tuthill et $a l^{72}$ reported an 18year-old woman with a 10-year history of a shoulder plaque that reached a size of $10 \mathrm{~cm}$ before excision; the lesion was of variegated shades of brown, blue, and black comprising beaded rows of papules and macules. At 1 year after the initial excision, a cutaneous metastasis developed at the graft site. Levene described a progressive punctate dermal melanocytosis that started in childhood and terminated in the fifth decade as disseminated melanoma. Pathy et $a l^{73}$ described a 65-year-old man who developed numerous nodules in the periphery of a giant blue nevus of the scalp that had been present since childhood. His subsequent course was one of local satellite metastases and of subsequent spread to cervical lymph nodes and parotid gland.

\section{Histology}

The animal-type melanoma is a heavily pigmented tumor that extends to the dermal subcutaneous interface and often lacks a grenz zone of papillary dermal sparing (Figures 21 and 22). Pagetoid infiltration of a hyperplastic epidermis may be seen. Tumor cell cytoplasms manifest pigment deposition that ranges from fine granular deposits of light brown melanin to dark brown coarse deposits that obscure nuclear detail. The latter, when manifesting polygonal or rounded cytoplasmic contours, are difficult to distinguish from the melanophages present in variable numbers in all cases. The tumor cells have either a spindled or a polygonal morphology, the spindled cells frequently being disposed in fascicles. The population with a rounded or polygonal contour often assumes a nodular disposition within the dermis. Areas of confluent melanocytic growth are invariably present and typically dissipate in cellularity at the periphery of the lesion where the cells manifest a dendritic appearance that may be mistaken for a blue nevus. Mitotic activity is usually very low, a host response is negligible, ulceration is never seen, and intravascular invasion is not identified. The dominant cytomorphology in most cases is that of cells that show some nuclear 


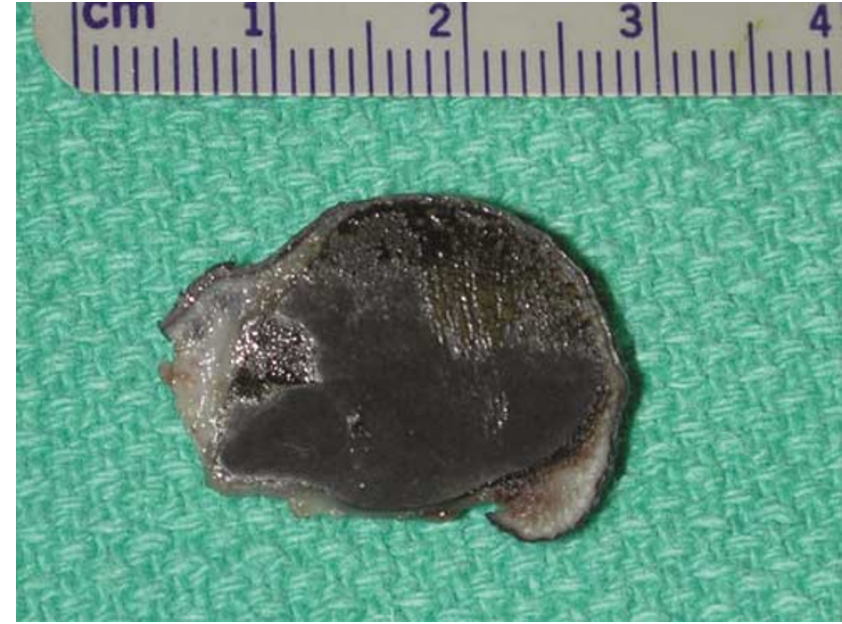

Figure 21 Melanoma with prominent pigment synthesis (animaltype melanoma). This particular tumor shows a $2.5 \mathrm{~cm}$ diameter black nodule extensively replacing the dermis and upper subcutis.

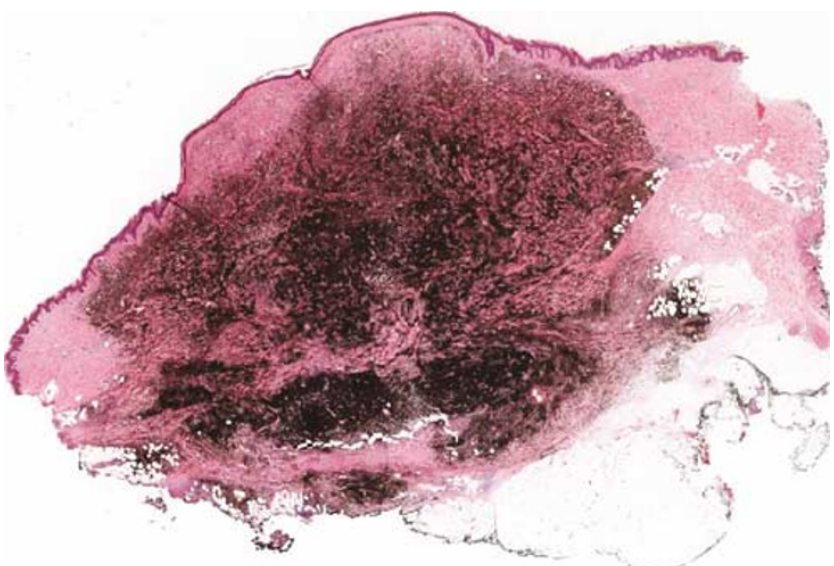

Figure 22 Melanoma with prominent pigment synthesis ('animaltype melanoma'). The tumor diffusely replaces the dermis and the upper subcutis and manifests prominent pigment deposition which obscures nuclear detail.

atypia, namely, regular oval to round nuclear shapes, with moderate anisonucleosis, small nucleoli, and delicate, evenly distributed chromatin; characteristically, these do not fulfill the cytologic criteria of malignancy (Figures 23-25). In roughly half of cases the cytomorphology was recognizably malignant but nonetheless well differentiated; bizarre or overt anaplasia is not a feature, in our experience, except in metastatic deposits. Rather, the most important clue to the diagnosis of melanoma is effacement of dermal architecture by areas of confluent melanocytic growth. There is a propensity for tumor cells to infiltrate the adventitial dermis of follicular and adnexal structures. The close association of the tumor cells to the follicular

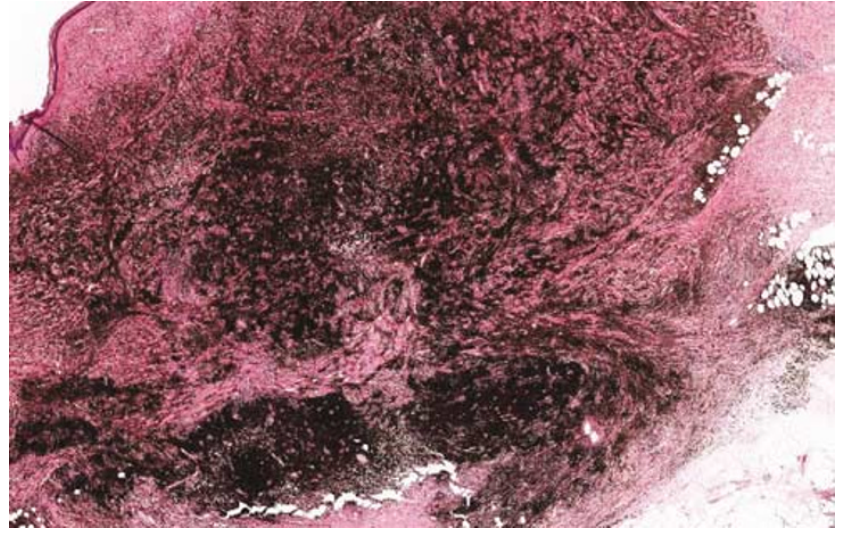

Figure 23 Melanoma with prominent pigment synthesis (animaltype melanoma). Heavy melanin pigment obscures nuclear detail.

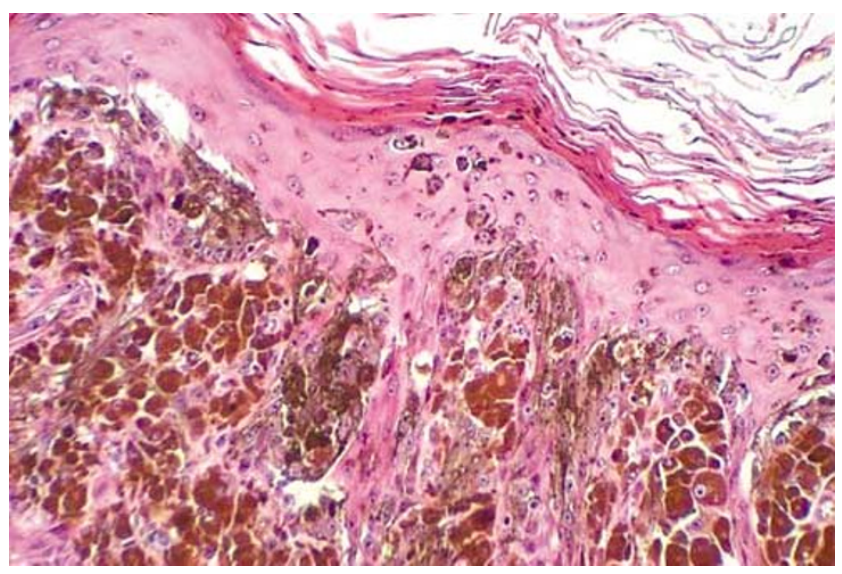

Figure 24 Melanoma with prominent pigment synthesis (animaltype melanoma). Roughly one-third to one-half of cases have an epidermal component with prominent pagetoid spread. In this example, the heavily melanized cells manifest prominent dendritic processes within the epidermis.

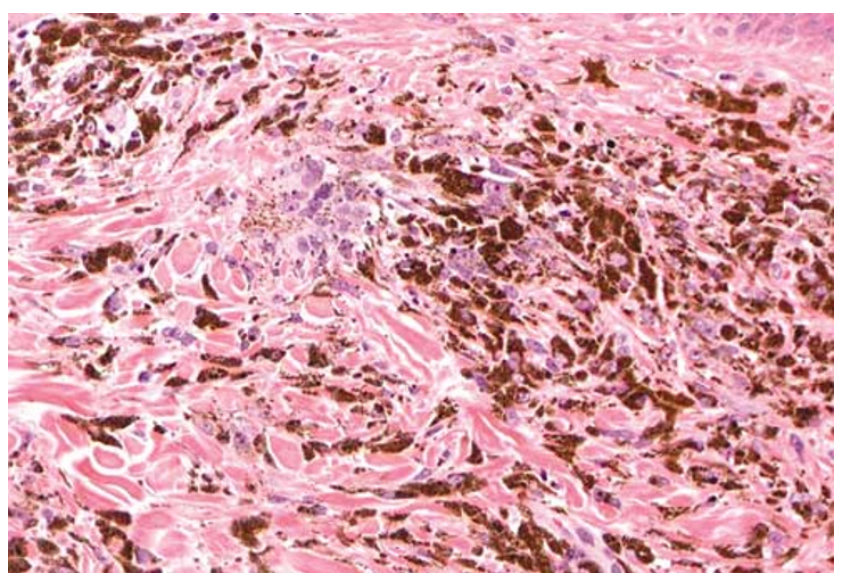

Figure 25 Melanoma with prominent pigment synthesis (animaltype melanoma). Where nuclear details can be discerned, the nuclei are clearly atypical and large with high nucleocytoplasmic ratios and prominent nucleoli. Melanin bleach preparations can be employed to remove the pigment, and thus to identify mitotic activity. 
sheaths has prompted an alternative appellation for this neoplasm, namely, pilar neurocristic hamartoma. ${ }^{65,71,73,74}$ The latter is apparently a hamartomatous lesion in which melanoma with prominent melanin synthesis may arise; some cases of animaltype melanoma develop in the setting of a hybrid pattern of blue nevus with a background perifollicular and perieccrine population of well-differentiated pigment-laden cells which seem to give rise to the foci of melanoma. Metastases have a variable morphology in this scenario, whereby some deposits resemble pilar neurocristic hamartoma and others are typical of melanoma. Malignancy developing in other prominent pigment-synthesizing tumors is described for cellular blue nevi, ${ }^{75,76}$ extrasacral mongolian spots, and the nevi of Ota and Ito. ${ }^{77}$ Precursor dysplastic, common acquired, or congenital nevi have not been identified. The typical case lacks melanoma in situ like nodular melanoma, but there may be pagetoid spread centrally overlying massive dermal involvement. One case in our series had a precursor lesion suggestive of a cellular blue nevus, whereas three other cases had areas recapitulating the morphology of a common blue nevus. ${ }^{71}$ Other authors have reported an apparent relationship with blue nevi, suggesting a common histogenetic precursor, namely, the dermal dendritic melanocyte. Perhaps these tumors should be considered a form of aggressive dermal melanocytosis with a potential to metastasize. ${ }^{78}$ In our experience, those cases with bland cytomorphology did not manifest aggressive behavior, whereas, of those cases with overtly anaplastic nuclei, one showed intracutaneous metastatic disease and one led to death from metastasis.

\section{Differential Diagnosis}

The differential diagnosis of such lesions includes cellular blue nevus, blue nevus with hypercellularity, the heavily pigmented epithelioid cell nevus, and regressed melanoma with prominent melanophage accumulation..$^{79-82}$ Cellular blue nevus manifests nests of cells with monotonous round to oval nuclei, bland, evenly dispersed chromatin, and abundant quantities of clear cytoplasm with well-defined cell margins arranged in discrete nodules. There is an interposition by components typical of a common blue nevus and nests of melanophages in the stroma between tumor nodules. The cellular blue nevus typically assumes a 'dumbbell'-shaped configuration that is vertically oriented. The cellular foci may be relatively devoid of pigment synthesis, the foci of prominent pigment synthesis being identified in the more hypocellular blue nevus-like areas. The blue nevus with hypercellularity resembles a common blue nevus but also contains cellular fascicles of relatively amelanotic spindled cells. The blue nevus with hypercellularity is not as large as a cellular blue nevus and fails to demonstrate the dumbbell-shaped configuration that is typical of the cellular blue nevus. The heavily pigmented epithelioid cell nevus is usually well circumscribed, with either a rounded or wedge-shaped lower border, and the cells, where visible, have a bland cytomorphology. Although we have encountered a case of animal-type melanoma with a whorled, or storiform, low-power architecture, we do not consider the Bednar tumor (pigmented dermatofibrosarcoma protuberans) to be a realistic differential diagnostic consideration. The reason for this is that the dendritic pigmented cells scattered throughout the Bednar tumor are incapable of producing a sufficient quantity of melanin to obscure nuclear features. If in doubt, the critical cells in the Bednar tumor mark, as expected, with antibody to CD34. ${ }^{83}$

Features of regressed vertical growth phase melanoma include a distinctive pattern of delicate fibrosis comprising fine collagen fibers amidst an edematous matrix that contains scattered mononuclear cells. Prominent elongated venules are present, often with a perpendicular arrangement to the epidermis. Amidst these stromal alterations are accumulations of pigment-laden macrophages that can assume a globular architecture similar to animal-type melanoma but lack nuclear atypia. The nuclei of the critical cells of animal-type melanoma are variable in size and shape but never include those with the reniform contour of a histiocyte. In regressed melanoma, the melanin pigment is coarse and irregularly distributed within the cytoplasms of melanophages, which contrasts with the fine granular pattern of deposition seen in the neoplastic melanocytes in animal-type melanoma. Immunohistochemical stains would be confirmatory of the dominant histiocytic composition of the infiltrate in regressed melanoma; the dominant cell type in lesions of equine melanoma is a spindled melanocyte. We recommend the use of an alternate chromagen to diaminobenzidene, because the brown reaction product of this chromagen may be difficult to visualize in the melanized tumor. One alternative choice for a chromagen is aminoethylcarbazole, which decorates the reaction product with a distinct reddish-brown color. Another would be a streptavidin-alkaline-phosphatase system followed by new fuschin chromagen (Bio Genex Laboratories, San Ramon, CA, USA), which imparts a distinctive purplish hue to the reaction product. A third alternative that we employ is the alkaline phosphatase system using Fast Red chromagen (Ventana Medical Systems Inc., Tucson, AZ, USA). We do not recommend the use of permanganateoxalate bleach methods to remove the melanin pigment, as their use causes loss of decoration with antibodies MelanA and HMB-45. Although S100 protein antigenicity is maintained in permanganateoxalate bleach methods, the specificity of S100 expression as an indicator of melanocytic differentiation is, of course, less. 


\section{Management and Prognosis}

The biological behavior of animal-type melanoma is hard to predict given the small series in the literature. There is some evidence, albeit not of a statistically significant character, that tumors with less atypical cytologic characteristics behave in a more indolent fashion than those with overtly malignant nuclear features. Although the tumor can be lethal, given the depth and level of reported lesions and the lack of a host response, it would seem that in most instances the course is less aggressive than that of nodular or superficial spreading vertical growth phase melanomas with similar histologic parameters. Lesions of animaltype melanoma manifest a low mitotic index and lack regression, vascular invasion, or ulceration. As there is a potential for aggressive behavior that cannot be reliably predicted on the basis of histologic criteria, we advise re-excision of all animal-type melanomas with 1-2-cm margins. Sentinel lymph node biopsies are also probably of value and should be performed in cases where this procedure is available. A recent study of heavily pigmented epithelioid melanocytic neoplasms, lumped together under the common term 'pigmented epithelioid melanocytoma,' showed regional lymph node metastases in $46 \%$ of cases in which lymph node biopsies were performed. Only 24 of 40 patients in that series underwent lymph node biopsies, however, suggesting that this grouping of lesions included those known or thought most likely to have no metastatic potential. ${ }^{84}$ In an earlier study, seven of 10 patients with pigment-synthesizing tumors who underwent sentinel lymph node biopsies were found to have metastatic tumor deposits. ${ }^{85}$ Follow-up, as in any case of invasive malignant melanoma, should be conducted.

\section{Malignant blue nevus}

\section{Introduction and Clinical Features}

The malignant blue nevus is a rare lesion first described by Allen and Spitz ${ }^{86}$ that usually arises in a background of cellular blue nevus. ${ }^{87-97}$ These lesions are most common on the scalp, although they have been reported at other sites such as the arm (Figures 26 and 27). ${ }^{98}$ In only rare cases will a malignant blue nevus arise de novo with no apparent benign precursor, and in such circumstances, an alternate label or diagnosis should be considered. Although the precursor lesion has invariably been present since birth or early childhood, malignant transformation occurs in an age group typically greater than 45 years, ${ }^{94}$ with a male preponderance. The clinical hallmarks of malignant cellular blue nevus include rapid enlargement, ulceration, and change in color. The lesions may attain a large size $(3-13 \mathrm{~cm})$. The tumor is thought to have an aggressive behavior and metastasizes in the

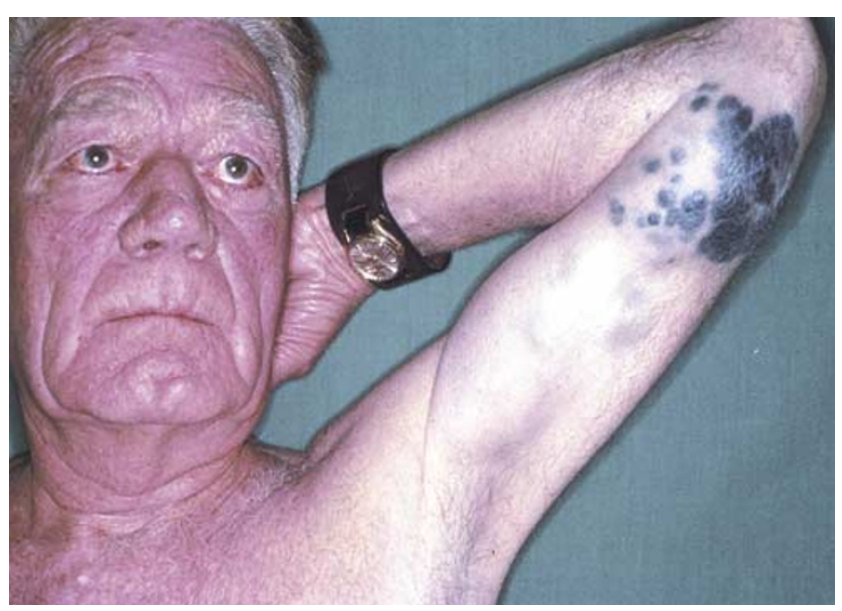

Figure 26 Malignant blue nevus. This elderly man's longstanding blue nevus underwent progressive expansion to a size of over $12 \mathrm{~cm}$ and developed multiple blue-black satellite nodules within it. (Case courtesy of Dr Mirek Stranc, Winnipeg, Manitoba).

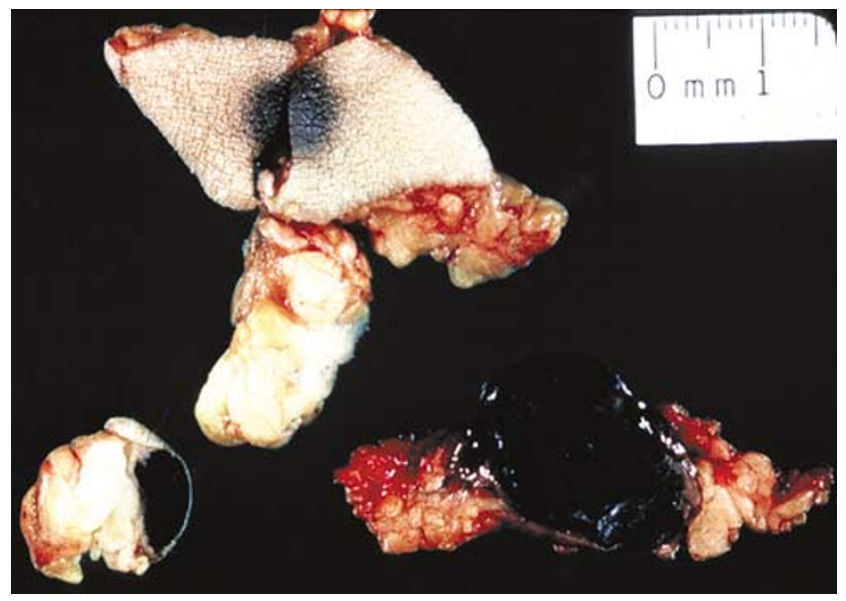

Figure 27 Malignant blue nevus. Note the blue-black nodule with a surface diameter in excess of $1 \mathrm{~cm}$ and a supero-inferior dimension of $1.5 \mathrm{~cm}$, as tumor infiltrates the subcutaneous tissue. (Case courtesy of Dr Mirek Stranc, Winnipeg, Manitoba).

majority of patients. ${ }^{98-100}$ Molecular analysis following microdissection has failed to show loss of heterozygosity for a number of genes operative in melanomagenesis, such as MTS1, MX11, CMM1, p53, NF1, L-myc, hOCG1 and MCC. ${ }^{97}$

\section{Histology}

There is typically a background lesion consistent with a cellular blue nevus (Figure 28), ${ }^{90,95-97}$ usually situated laterally to the malignant component. Occasional examples have been seen superimposed upon pre-existing nevi of Ito or Ota. ${ }^{77,101}$ An exceptional case may arise in the background of a dermal melanocytosis in other settings, such as in a nevus spilus. ${ }^{102}$ In most cases a moderately dense inflammatory cell infiltrate is present at the base. The histologic features of the benign component, be 


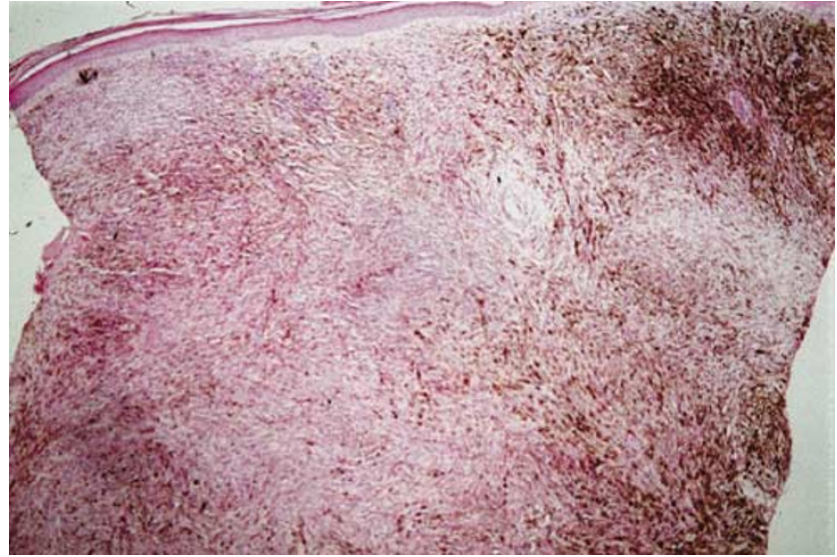

Figure 28 Malignant blue nevus. In this example there is heavy pigment synthesis within the dermis. The central area of depigmentation represents a zone of confluent necrosis which is characteristic of malignant blue nevus; the peripheral aspects show more typical blue nevus and/or cellular blue nevus.

it a blue or cellular blue nevus, are prototypic for the respective entity. Amidst this precursor lesion are fascicles and nodules of markedly pleomorphic spindle and epithelioid cells, the former cell type dominating in the fascicular component and the latter being primarily found within the nodular areas. The fascicles and nodules coalesce, resulting in effacement of the dermal architecture. This form of malignant melanoma frequently exhibits extension into the subcutis. There are interspersed bizarre tumor giant cells. Numerous abnormal mitotic figures are observed, averaging 8-9 per $\mathrm{mm}^{2}$ (Figure 29). ${ }^{92}$ Zones of tumor cell necrosis are observed. There may be blood vessel invasion. A junctional component is typically absent. ${ }^{94}$

\section{Differential Diagnosis}

The differential diagnosis is primarily with a cellular blue nevus with atypia ${ }^{92,103,104}$ vs the animal-type melanoma. ${ }^{71}$ In the atypical cellular blue nevus there is a minor component that appears very similar to a malignant cellular blue nevus as manifested by marked pleomorphism, the presence of bizarre giant cells, and atypical mitoses. Such atypical cells are the dominant component in malignant cellular blue nevus but in contrast comprise only a small component of the cellular blue nevus with atypia. Possibly, the latter represents a cellular blue nevus in transition to a malignant cellular blue nevus. The main differentiating points, in addition to the extent of the cytologic atypism in the lesion, are large areas of necrosis, a high mitotic rate, blood vessel invasion, and cytologic atypia with nucleolar prominence. The animal-type melanoma typically has less atypical cytology and a lower mitotic rate, nor does it manifest confluent necrosis as does the malignant blue nevus. ${ }^{19,71}$ The diagnosis of malignant blue

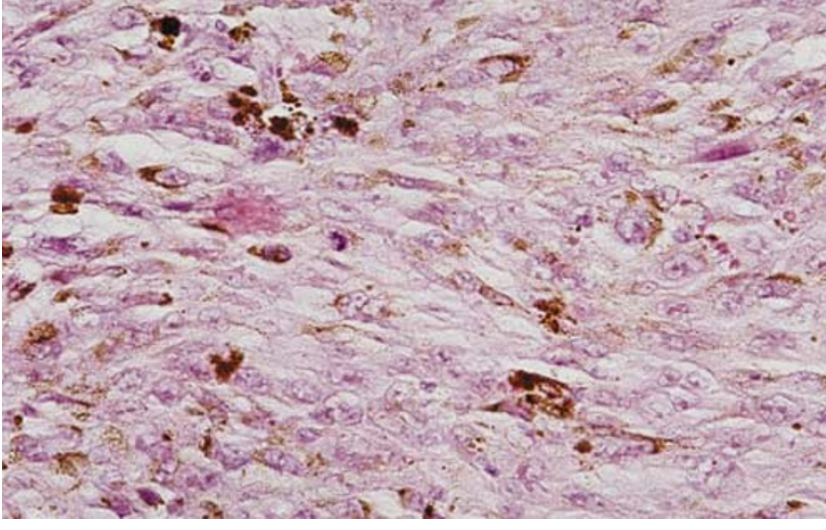

Figure 29 Malignant blue nevus: Where nuclear preservation is optimal, mitotic figures can be seen and the fully transformed malignant cytology of this lesion can be appreciated.

nevus should be considered when a lesion that has arisen in a pre-existing blue or cellular blue nevus exhibits highly atypical epithelioid melanocyte with bizarre tumor giant cells and numerous abnormal mitotic figures averaging 8-9 per $\mathrm{mm}^{2}$.

It should be remembered that cellular blue nevi can be associated with rests within lymph nodes, ${ }^{81}$ mimicking metastatic disease.

\section{Unusual cytmorphologic and phenotypic variants of melanoma (metaplastic, balloon, signet ring, myxoid, small cell, and rhabdoid melanoma)}

\section{Unusual Phenotypic Profiles in Malignant Melanoma}

The spectrum of abnormal phenotypes which can be encountered in melanoma include the expression of morphologies and antigens more commonly encountered in lesions of epithelial, fibrohistiocytic, rhabdoid, smooth muscle, and osteocartilagenous derivation. Conversely, some melanomas do not express markers commonly associated with melanocytic phenotypes (ie S100 protein or HMB45) and thus prove to be particularly treacherous diagnostic pitfalls.

\section{Metaplastic Change in Malignant Melanoma}

Metaplastic foci mimicking osteogenic sarcoma have been described in lesions of malignant melanoma. Some of these cases were associated with external iatrogenic procedures, suggesting the role of trauma as an inducing factor (Figure 30). ${ }^{105-111}$

Osteosarcomatous metaplasia in a malignant melanoma may be the sequela of an alteration in benign stromal fibroblasts as a host response to the tumor, or it could represent a divergent differentiation pattern, whereby melanoma cells acquire the machinery necessary for the production of malignant osteoid. Cartilaginous metaplasia has also been 


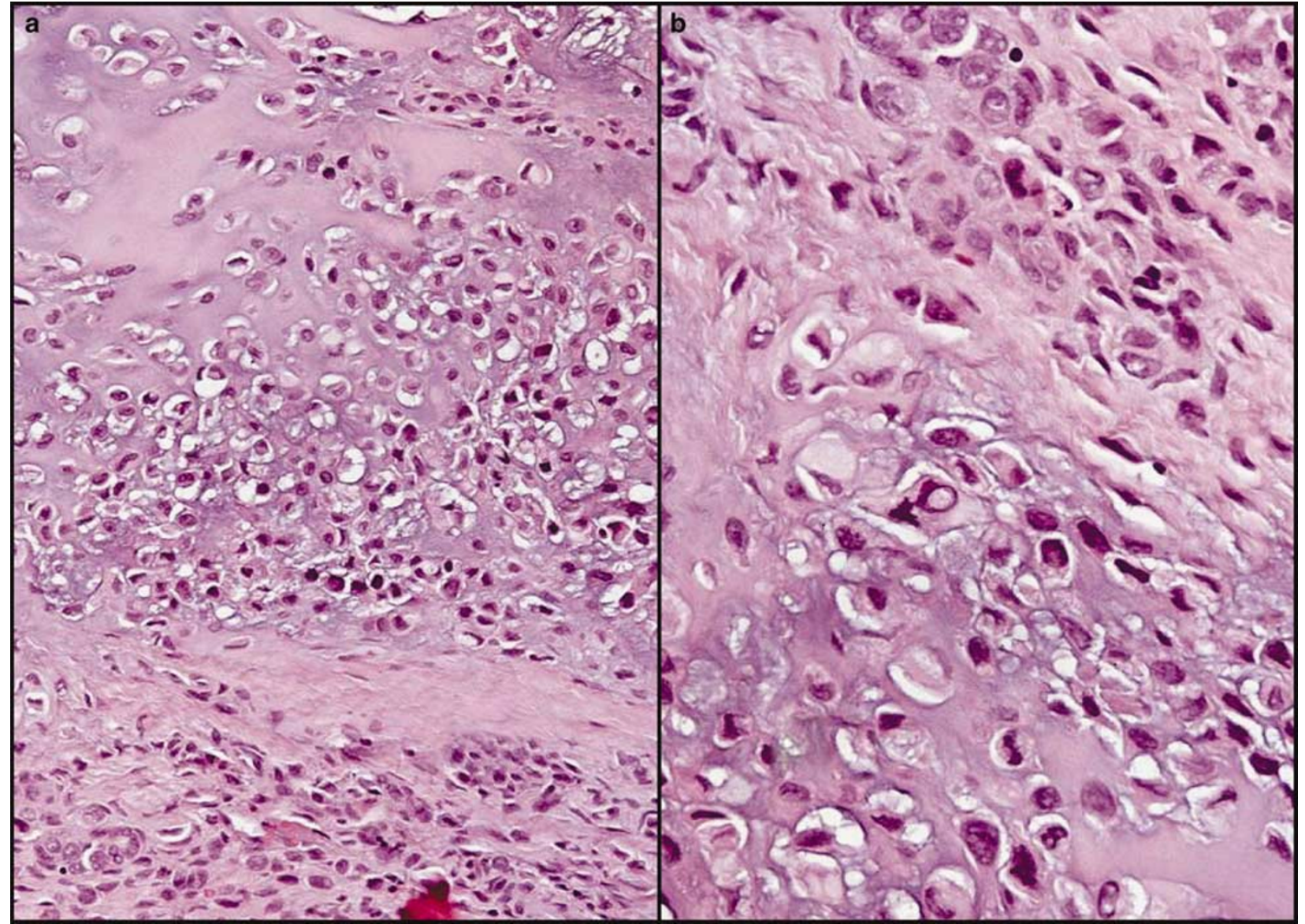

Figure 30 Metaplastic melanoma: In this subungual melanoma, extensive cartilaginous matrix is produced by the neoplastic melanocytes (a). Malignant cytologic features are visible at intermediate and high power microscopy (b).

described, ${ }^{106,110,112}$ often combined with bone formation to yield a form of osteocartilaginous metaplasia, such as that reported in one case of a nasal mucosal primary and its metastasis ${ }^{110}$ and in cases of subungual melanoma. ${ }^{111,112}$ Mesenchymal elements with rhabdomyoblastic, lipoblastic, and neurogenous features have been described in those malignant melanomas that arise in giant congenital nevi. ${ }^{113}$

\section{Balloon Cell Melanoma}

\section{Clinical features}

Balloon cell melanoma is a rare form of vertical growth phase melanoma characterized by a nodular proliferation of neoplastic balloon cells; the background lesion is typically one of a superficial spreading melanoma. ${ }^{114}$ Clinically, lesions appear as soft, rubbery, or firm nodules with a polypoid or papillomatous contour whose cut surfaces are grayish white or brown. ${ }^{115}$ The prognosis is similar to that of other types of melanoma matched for depth of invasion, with tumor thickness being of greatest importance and the poor patient survival statistics usually reflecting the deep extent of the tumor at the time of presentation. In the largest series on record, $57.5 \%$ of patients died with metastatic disease 2 months to 12 years after initial surgery. ${ }^{115}$ Primary balloon cell melanoma in brain arising from a melanoblastic meningeal (or diffuse meningeal) nevus has been described. ${ }^{116}$ Amelanotic balloon cell melanoma represents a common histologic variant in the spectrum of feline malignant melanoma ${ }^{117}$ and has also been described in humans. ${ }^{118}$ This unusual neoplasm has been reported in the choroid. ${ }^{119,120}$

\section{Histology}

The tumor is characterized by nests and sheets of large cells that exhibit an abundant quantity of clear or finely vacuolated cytoplasm (Figure 31). The lesion resembles a balloon cell nevus, although there are important distinguishing features. In particular, there is effacement of dermal architecture by sheets of neoplastic cells with no intervening stroma. Cytologic atypia and mitotic activity are present, and necrosis, when visible, is a helpful sign. The nuclei are large and exhibit prominent nucleoli and highly irregular chromatin patterns. 


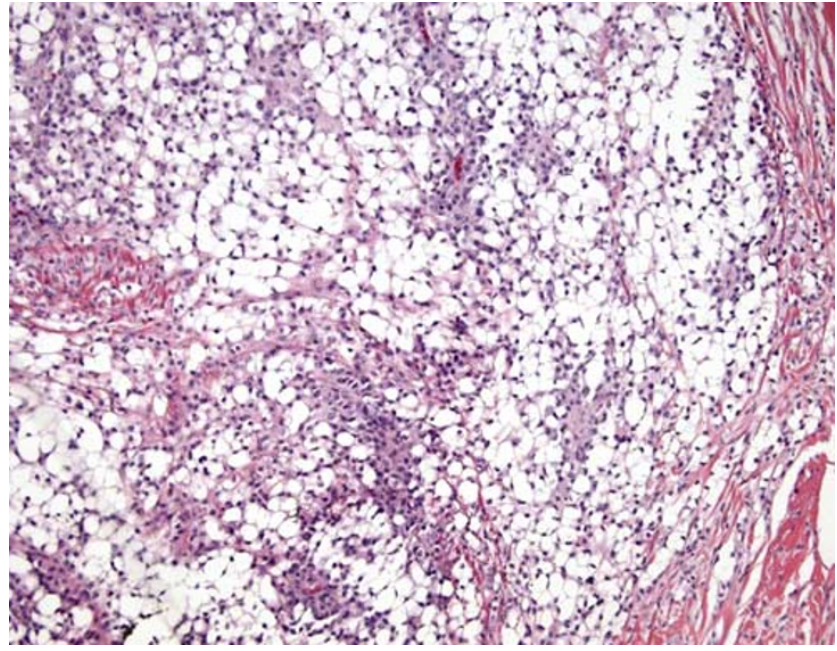

Figure 31 Balloon cell melanoma: The vertical growth phase of balloon cell melanoma is characterized by clear or empty cytoplasmic spaces which indent and displace the nucleus to the peripheral margin of the cell. In some areas, conventional epithelioid vertical growth phase melanoma can be identified.

The clearness of cytoplasms in some cases appears to be due to the intracellular accumulation of glycogen as characterized by strong diastase-sensitive periodic acid-Schiff positivity. ${ }^{121}$ In the majority of ultrastructural studies, however, the vacuoles either appear empty or are held to represent degenerating melanosomes in a fashion analogous to the balloon cell change of benign nevi. ${ }^{115,120,122}$ This is also likely true of most metastases from balloon cell melanomas, which in one report did not contain glycogen, fat, or melanin. ${ }^{118}$ In another case of metastatic balloon cell melanoma, however, the tumor cells were shown by electron microscopy to contain lipid. ${ }^{123}$ Immunohistochemical studies with antibodies to S100 protein, Melan-A and HMB-45 are positive in balloon cell melanoma and its metastases (Figure 32), ${ }^{115,118,124,125}$ whereas neuronspecific enolase preparations tend to decorate cells weakly. ${ }^{115}$

\section{Differential diagnosis}

The differential diagnosis encompasses balloon cell change in benign nevi including blue nevi ${ }^{122}$ and common acquired nevi, with which balloon cell melanoma may coexist, ${ }^{125}$ as well as other malignant clear cell neoplasms. The latter include clear cell sarcoma of soft parts, atypical fibroxanthoma and granular cell carcinoma with clear cell change, metastatic renal cell carcinoma, clear cell basal cell carcinoma, and malignant clear cell acrospiroma ${ }^{115}$ as well as sebaceous carcinoma and clear cell squamous cell carcinoma. Benign nonmelanocytic lesions that merit consideration include lepromatous leprosy, xanthomata and hibernomas, ${ }^{115}$ and clear cell dermatofibroma. ${ }^{126}$ Regarding the latter, overlying epidermal hyperplasia and a storiform

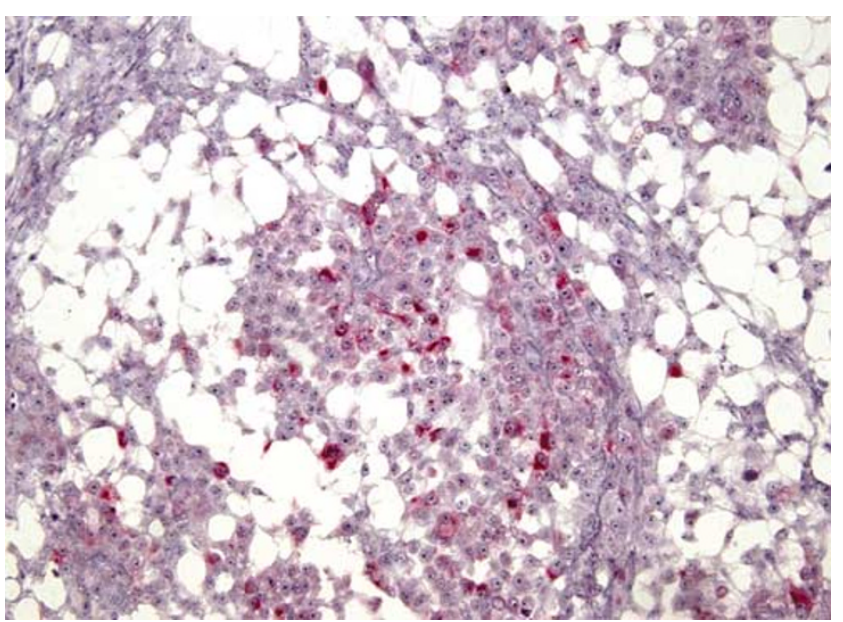

Figure 32 Balloon cell melanoma: Melan-A immunohistochemical preparation. Although the balloon cell areas typically are Melan-A and HMB 45 negative, the more conventional epithelioid vertical growth phase zones show cytopasmic expression of Melan-A in this figure, attesting to their melanocytic derivation. The balloon cell change is largely attributed to degeneration of melanosomes and their phagocytosis within lysosomal structures, thus perhaps explaining the relative lack of expression of MelanA and HMB 45.

arrangement of spindle cells amidst sclerotic stroma typical of a benign fibrohistiocytic neoplasm are characteristic. The critical cells in clear cell dermatofibroma are factor XIII positive. ${ }^{126}$ Balloon cell melanoma cells can mimic foamy histiocytes at fineneedle aspiration biopsy, ${ }^{127}$

\section{Signet-Ring Melanoma}

A signet-ring morphology may be observed in lesions of melanoma and most commonly reflects metastatic or recurrent lesions (Figure 33). ${ }^{128,129}$ The finding of signet-ring differentiation in malignant melanoma is an unusual event, being seen in some $0.5 \%$ of melanomas. ${ }^{128}$ Such findings raise diagnostic consideration of adenocarcinoma, particularly in metastatic sites ${ }^{129,130}$ and in pleural or peritoneal effusion cytology. ${ }^{131}$ The signet-ring cells may have a small cell, large cell, or giant cell morphology. Ultrastructural examination reveals that the vacuolated appearance is most often imparted by the intracytoplasmic accumulation of intermediate filaments, specifically, vimentin. ${ }^{132,133}$ The cells characteristically decorate with antibodies to S100 protein and are HMB-45 positive; however, exceptions to this profile exist. For example, cases of S100-positive, HMB-45-negative signet-ring melanoma are described ${ }^{134,135}$ as are cases of HMB-45positive, S100-negative signet-ring melanoma. ${ }^{136}$ In rare examples, intracytoplasmic neutral mucin may be observed. The differential diagnosis of signet-ring melanoma includes neoplasms with prominent cytoplasmic vacuolation; tumors of vascular 
endothelium or adipose tissue, signet-ring lymphoma, ${ }^{137}$ and epithelioid smooth muscle lesions are thus considered as well as the obvious signet-ring

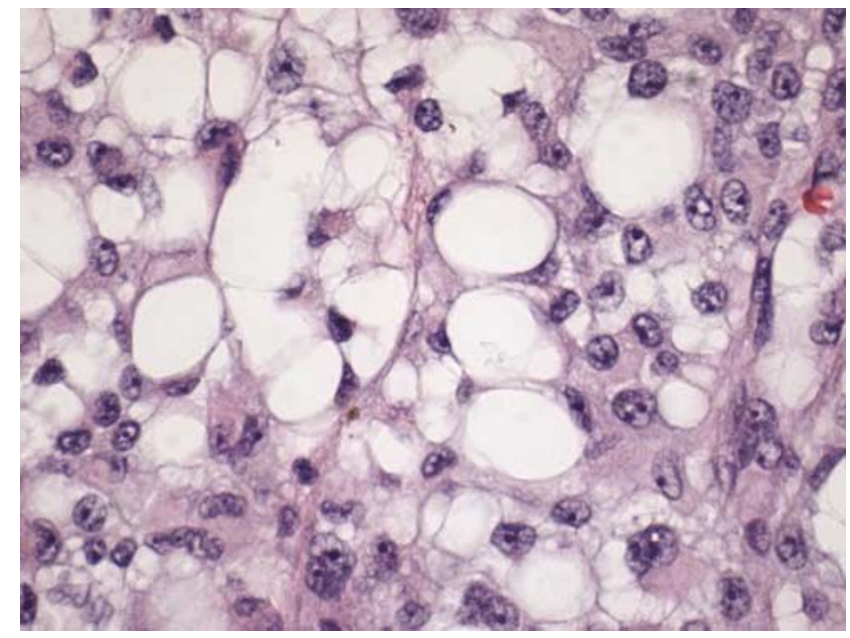

Figure 33 Signet-ring melanoma. In signet-ring melanoma, as in balloon cell melanoma, a large vacuole displaces the nucleus to the periphery of the cell; however, the tumor cells may also have a bubbly, or physaliferous morphology. In this case, the bubbly morphology and the cytoplasmic vacuolization is attributable to the accumulation of aggregates of vimentin filaments, as proven at the ultrastructural level. adenocarcinoma. ${ }^{138}$ This is a common histologic variant in malignant melanoma in animal models. ${ }^{117}$

\section{Myxoid Melanoma}

\section{Introduction and clinical features}

Most often, the myxoid melanoma presents as a metastatic tumor deposit that is associated with a primary neoplasm that does not manifest a myxoid morphology. ${ }^{139}$ However, primary myxoid melanoma has also been described in the $\operatorname{skin}^{128,140-147}$ and in extracutaneous sites including the sino-nasal passages. $^{148}$

\section{Histology}

The rare myxoid melanoma manifests large malignant cells amidst a basophilic mucinous matrix. In all cases, the myxoid stroma comprises mesenchymal acidic mucopolysaccharides, as opposed to neutral epithelial mucins (Figure 34). Thus, epithelial mucin preparations such as mucicarmine and PAS-diastase are negative, whereas stains for acidic mucosubstances (ie, Alcian blue at low $\mathrm{pH}$ ) are positive. The tumors are essentially amelanotic, although by Fontana Masson preparations some manifest evidence of melaninogenesis. Melano-

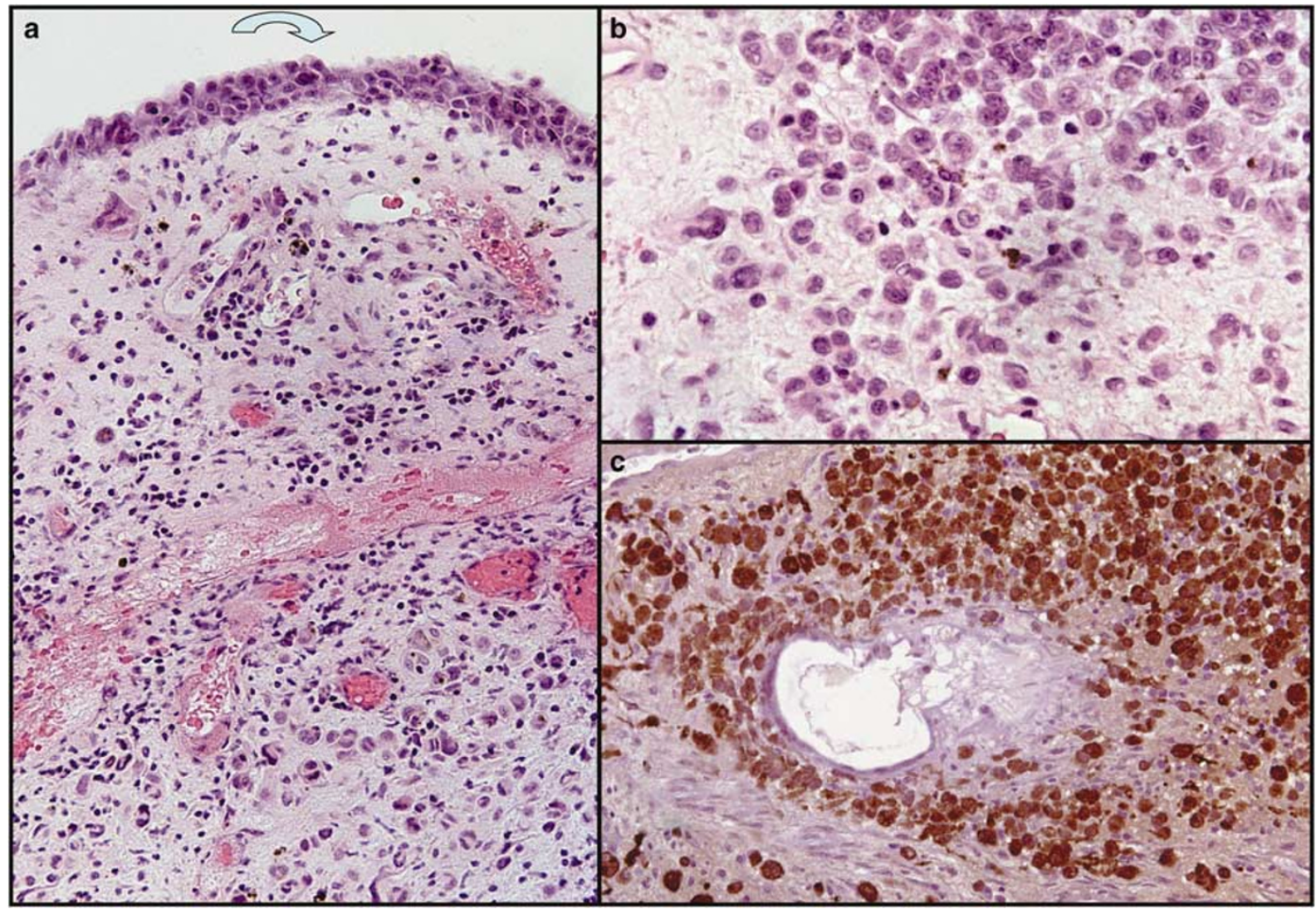

Figure 34 Myxoid melanoma: In this mucosal melanoma from the nasopharynx, there is lentiginous melanocytic hyperplasia with fully transformed malignant cells within the epithelial compartment (curved arrow, a). The myxoid change is seen in the epithelioid vertical growth phase areas where an abundant quantity of acid mucosubstances is deposited in the subepithelial stroma (b). The tumor cells show strong decoration with antibody to S100 protein (c). 
somes, including aberrant variants, are demonstrable by electron microscopy. ${ }^{139,146}$ As there is no cytoplasmic localization of the mucinous material within the tumor cells, it is likely that the myxoid matrix is produced as a response of the stromal cells to the tumor rather than being a product of the tumor cells per se. Such lesions should prompt evaluation for a primary malignant melanoma because they most often represent metastatic tumor deposits. ${ }^{128,139,149-154}$ Recently, a myxoid variant of clear cell sarcoma, the soft tissue counterpart of cutaneous melanoma, has been described. ${ }^{155}$

Distinction of primary from secondary myxoid melanoma rests on the demonstration in the primary lesions of an atypical intraepidermal melanocytic proliferation. ${ }^{141}$ The pattern of intraepidermal melanocyte proliferation can be subtle, with irregular nesting that is only focal. ${ }^{146}$ The lesions are usually sparsely melanized or amelanotic; some show neurotropism. ${ }^{146}$ Typically, ubiquitous S100 decoration can be demonstrated. Decoration with HMB-45 is less uniform, however, with both positive ${ }^{139}$ and negative $^{146}$ results reported. In our hands, S100 protein was ubiquitously expressed in myxoid melanomas, while only two-thirds expressed lineage-specific markers Melan A or HMB $45 .{ }^{156}$ One group found that labeling of primary myxoid melanomas with E9, an antimetallothionein marker, was predictive of rapid progression. ${ }^{146}$

\section{Differential diagnosis}

The differential diagnosis of myxoid melanoma is broad, encompassing as it does other benign and malignant myxoid neoplasms. With respect to the latter, the spectrum includes soft tissue malignancies as well as epithelial cancers. The soft tissue malignancies include myxoid liposarcoma, ${ }^{157}$ myxoid malignant fibrous histiocytoma ${ }^{158}$ and its allied lesions, low-grade fibromyxoid sarcoma ${ }^{159,160}$ and low-grade myofibroblastic sarcoma, ${ }^{161}$ myxoid chondrosarcoma, ${ }^{158,162}$ myxoid peripheral nerve sheath tumors, ${ }^{139}$ myxoid rhabdomyosarcoma, ${ }^{163}$ malignant myoepithelioma, ${ }^{164}$ myxoid synovial sarcoma, ${ }^{165}$ myxoid follicular dendritic cell sarcoma, ${ }^{166}$ myxoid dermatofibrosarcoma protuberans, ${ }^{167}$ metastatic chordoma, and its benign mimic, parachordoma. ${ }^{168-170}$ The epithelial cancers that may mimic myxoid melanoma include metastatic adenocarcinomas, discussed under the differential diagnosis of signet-ring melanoma (see above), and malignant sweat duct tumors including malignant mixed tumor. The very rare sarcomatoid variant of anaplastic large-cell Ki-1 lymphoma ${ }^{171}$ can also produce areas strikingly similar to myxoid melanoma at the light microscopic level.

Myxoid melanoma lacks the arborizing, delicate vasculature of the myxoid liposarcoma, and, although the latter may rarely present as a primary skin neoplasm, ${ }^{172}$ it usually has a manifestly different clinical presentation that should enable easy distinction. In any event, liposarcomas man- ifest weak cytoplasmic membrane rim staining with S100 protein quite unlike that seen in a melanocytic neoplasm. The myxoid malignant fibrous histiocytoma and other soft tissue cancers of myofibroblastic derivation are generally S100 negative and, like the liposarcoma, have a different pattern of clinical presentation in most cases. The atypical fibroxanthoma, a superficial cutaneous variant of malignant fibrous histiocytoma arising in the sundamaged skin of the elderly, can also have a myxoid morphology. The low-grade fibromyxoid sarcoma might be confused with myxoid melanomas having a high content of spindled cells and manifests strong vimentin immunoreactivity; ${ }^{159,160}$ however, all other melanocyte-related immunohistochemical markers, including S-100 protein, are not expressed. ${ }^{160}$ Similarly, S100 protein is not expressed in lowgrade myofibroblastic sarcoma, ${ }^{161}$ which may be closely allied to the fibromyxoid sarcoma in any event.

Extraskeletal myxoid chondrosarcoma has long been considered a distinctive form of low-grade sarcoma occurring in the deeper soft tissues of proximal extremities, limb girdle, and trunk. Larger series show the estimated 10-year survivorship to be only $70 \% .{ }^{162}$ Neoplasms tend to be weakly positive for antibodies to S100 protein in only a minority of cases $(38 \%)$, and cytokeratin (CK) preparations are negative. ${ }^{162}$ Myxoid malignant peripheral nerve sheath tumors may arise de novo or in the setting of neurofibromatosis. ${ }^{173,174}$ Rhabdomyosarcomas characteristically are glycogen rich and manifest an immunohistochemical profile (desmin +ve/S100 -ve) unlikely to be confused with melanoma. Malignant myoepithelioma manifests myxoid, spindled, epithelioid, and plasmacytoid zones in a solid or partly cystic lesion; cells tend to have an epithelioid/rhabdoid cytomorphology and to decorate with antibodies to S100 protein, smooth muscle actin, and CK. ${ }^{164}$ Myxoid synovial sarcoma tends to manifest as lacy cords of monophasic spindled cells embedded in a myxoid stroma. ${ }^{165}$ Some examples manifest a biphasic morphology. Synovial sarcoma, arising as it does in an undifferentiated mesenchymal precursor, can rarely present as a primary skin neoplasm. ${ }^{175}$ Roughly half of such lesions express S100 protein, whereas most also express CK and/or epithelial membrane antigen. ${ }^{165}$ A myxoid variant of the follicular dendritic cell sarcoma exists; these are malignant tumors of the follicular dendritic cell apparatus that may occur in extranodal sites. ${ }^{166}$ The tumor cells, dispersed as cords of slightly atypical spindled cells, manifest immunoreactivity for S100 protein and epithelial membrane antigen, as well as CD21 and CD35, respectively the Epstein-Barr virus receptor on $\mathrm{B}$ lymphocytes and a monocyte marker. ${ }^{166}$ Myxoid dermatofibrosarcoma protuberans is a challenging diagnosis as the lesion is CD34 negative, unlike its conventional counterpart. ${ }^{167}$ However, antibody to S100 protein does not decorate this lesion, which 
should make distinction from myxoid melanoma simple. Chordoma metastatic to the skin, classically from a primary tumor of sacrum or clivus, can produce an appearance quite like myxoid melanoma. Chains of cells are enmeshed in a myxoid stroma; the cells manifest physalliferous (ie, spongelike or bubbly) cytoplasmic vacuolation. Coexpression of S100 protein and CK enables distinction from myxoid melanoma. ${ }^{176-181}$ Histologically identical to chordoma at the light microscopic level is the parachordoma, a benign cutaneous neoplasm that most often is seen in the extremities adjacent to synovia, tendons, or osseous structures. ${ }^{169}$ The immunohistochemical profile may be similar to chordoma, which more frequently manifests expression of CK (98 vs 66\%) and epithelial membrane antigen (90 vs 20\%). ${ }^{169}$ This distinction is an important one, however, as the diagnosis of chordoma implies a metastatic malignant neoplasm. Parachordoma may in fact represent a variant of the benign myxoid neurothekeoma. Correlation with clinical history and imaging studies is thus of paramount importance.

The malignant neoplasms of the sweat gland and duct manifest keratin positivity in most cases, as do malignant mixed tumors and metastatic carcinomas such as those of breast and lung. Furthermore, epithelial mucins are the rule in these scenarios. One can discern the very rare sarcomatoid variant of anaplastic large-cell lymphoma from malignant melanoma based on S100 negativity as well as its expression of CD30 and, focally, of epithelial membrane antigen. ${ }^{171}$

Benign lesions that merit consideration in the differential diagnosis of myxoid melanoma include soft tissue myxoma, ${ }^{182}$ myxoid common acquired nevi, ${ }^{183}$ myxoid cellular blue nevi, ${ }^{184}$ myxoid neurothekeoma ${ }^{185}$ and hyaline-cell-rich chondroid syringoma. ${ }^{186}$ The soft tissue myxoma manifests bland stellate or spindled cells lacking cytologic criteria for malignancy and can so be distinguished from myxoid malignant melanoma. ${ }^{182}$ Similarly, the myxoid cellular blue nevus lacks cytologic features of malignancy. With regard to the myxoid neurothekeoma, this lesion tends to decorate with antibody to S100 protein, ${ }^{185}$ as does the hyaline-cellrich chondroid syringoma; ${ }^{186}$ the latter will also show keratin decoration in the modified myoepithelia that make up the cell populace, thus enabling distinction when the appropriate immunohistochemical cocktail is applied.

\section{Small Cell Melanoma}

Undifferentiated small cell melanomas are most frequently encountered in the setting of a malignant melanoma that has arisen in a giant congenital nevus (Figure 35), the characteristic clinical herald of which is the development of a protuberant and/or ulcerating nodule. ${ }^{19}$ The small cell foci may show

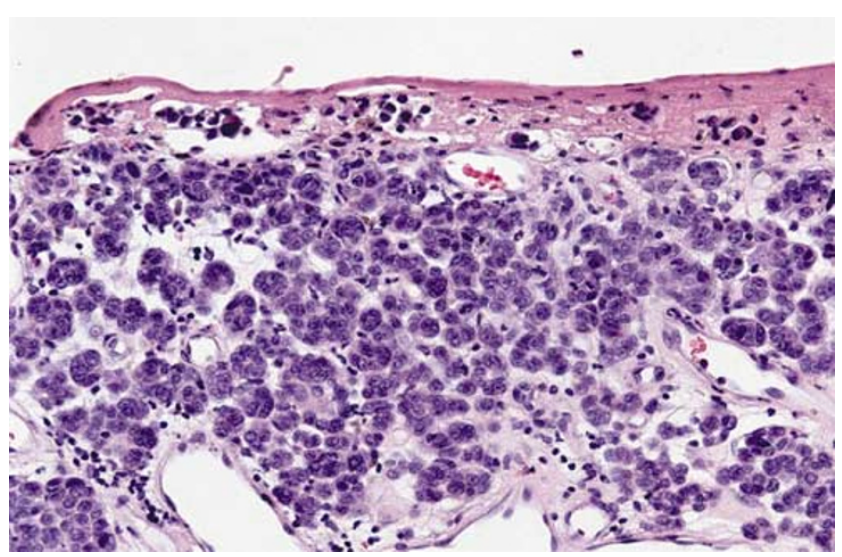

Figure 35 Small cell melanoma: In this small cell melanoma, which has arisen in the setting of a giant congenital nevus in an infant, the neoplastic melanocytes have nuclei only 2-3 times the diameter of red blood cells (ie roughly $20 \mu \mathrm{m}$ in size). They show nuclear contact molding and coarse heterochromatin cognate to a neuroendocrine cell carcinoma.

nuclear molding reminiscent of small cell carcinoma or exhibit a strikingly dyshesive growth pattern resembling the morphology of a lymphoblastic lymphoma. Melanomas manifesting this morphology are invariably in vertical growth phase and have an aggressive course. In addition to being a cytomorphologic mimic of lymphoblastic lymphoma, other small round cell tumors of childhood, including Ewing's sarcoma, peripheral neuroectodermal tumors, and Merkel cell carcinoma enter into the differential diagnosis of small cell malignant melanoma.

\section{Rhabdoid Melanoma}

The presence of rhabdoid features in melanoma has been described and is not uncommon in metastatic melanoma; however, it is quite rare in primary lesions with only a few cases reported. Rhabdoid tumors are characterized by large sheets of polygonal cells with abundant cytoplasm containing eosinophilic inclusions and a peripherally displaced vesicular nucleus (Figure 36). Ultrastructural analysis of one case showed cytoplasmic whorls of intermediate filaments with entrapped rough endoplasmic reticulum, mitochondria, and lipid. ${ }^{187}$ They have diverse patterns of immunoreactivity decorating with antibodies to S-100 and vimentin as well as, in some cases, keratins and desmin, and have been reported to frequently lose HMB- 45 expression. ${ }^{188}$

\section{CD34 Expression in Malignant Melanoma}

The CD34 antigen is a $110 \mathrm{kD}$ protein encoded by a gene located on chromosome 1q and expressed on the surface of stem cells in bone marrow. ${ }^{189}$ It was first used as a means to isolate stem cells for 


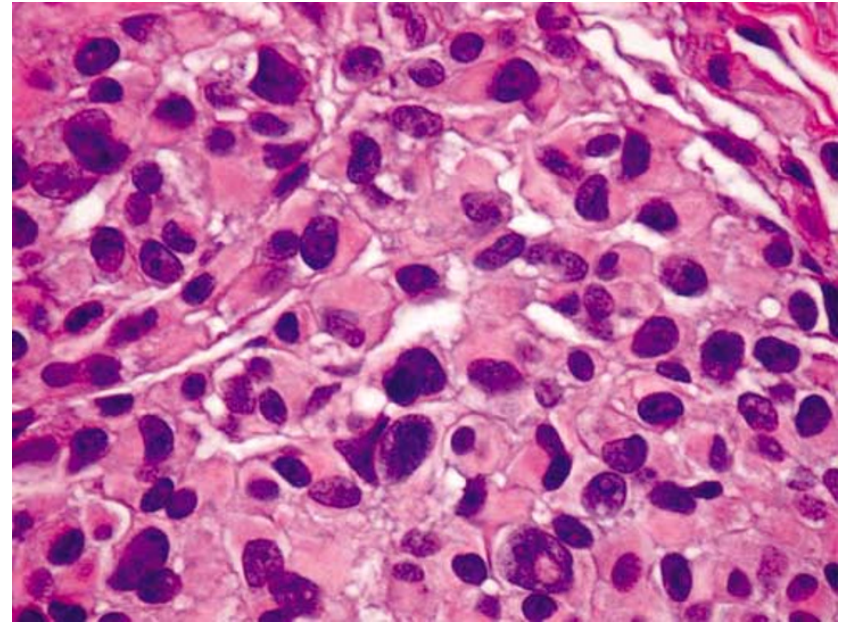

Figure 36 Rhabdoid melanoma: In this example of rhabdoid vertical growth phase melanoma, there are large eosinophilic inclusions in the cytoplasm in a fashion that mimics rhabdomyoblasts of rhabdomyosarcoma. At the ultrastructural level, these filaments are aggregates of vimentin; on occasion muscle-type intermediate filaments may also be seen. transplantation and to identify subgroups of acute leukemia. It is also found in vascular and spindle cell tumors as well as tumors of neural and myofibroblastic derivation including dermatofibrosarcoma protuberans (DFSP), solitary fibrous tumors and pleomorphic fibromas.

Melanocytic neoplasms have long been held to be CD34 negative, but there is a limited literature precedent regarding CD34 expression in lesions of melanoma (Figure 37). Hoang et al ${ }^{190}$ described a case of a desmoplastic malignant melanoma, resembling DFSP histologically, which expressed CD34 strongly in the tumor spindle cells. This further complicates an already difficult challenge of distinguishing a DFSP from desmoplastic melanoma as CD34 is often used as a marker of DFSP. ${ }^{191}$ Chen et $a 1^{192}$ described CD34 expression in uveal melanoma cells. The authors speculate that CD34 expression may be a marker of aggressive behavior. CD34 expression has also been described in a cellular blue nevus. ${ }^{193}$ CD34 is often used to calculate microvascular density in uveal tumors, one indica-

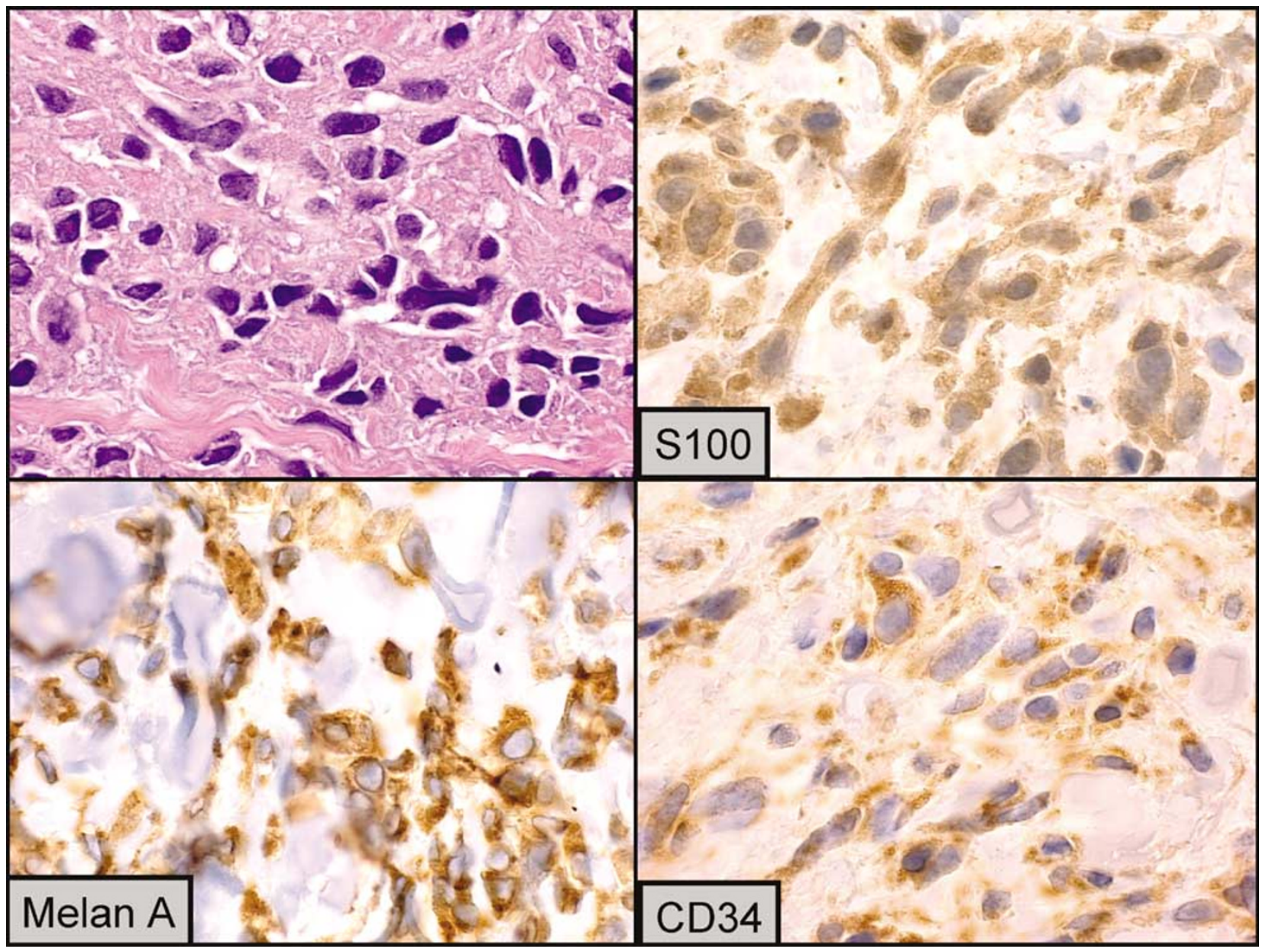

Figure 37 Aberrant CD-34 expression in melanoma. This melanoma expresses S100 protein and Melan-A immunohistochemically, but also shows florid expression of CD-34. 
tor of prognosis, ${ }^{194}$ owing to its expression in endothelia. ${ }^{195}$

The expression of CD34 in melanoma may be explained by genetic dysregulation. It has been shown that aggressive melanoma cells express inappropriate markers that would not be expected of normal melanocytes. ${ }^{196}$ Specifically, Hendrix et $a l^{196}$ showed expression of vascular endothelial (VE)-cadherin in aggressive melanoma cells which correlated with their ability to form vascular channels. The authors speculate that the expression of VE-cadherin may represent a reversion to a more primitive, embryonal phenotype. The expression of CD34 in melanoma may also be indicative of a similar state of dedifferentiation, as other cells of neural crest origin such as peripheral nerve cells and Schwann cells have been shown to express CD34. ${ }^{197}$

The Bednar tumor has also been shown to express a mixed immunophenotype (CD34- or Mart-1-positive) in dispersed dermal spindle cells within a DFSP-like lesion suggesting a common cell of origin, namely, a putative neuromesenchymal cell, the potential cell of origin of all neural crest-derived dermal tumors including DFSP. ${ }^{198}$ This overlap of histologic and immunohistochemical phenotypes may indicate the existence of a spectrum of neuromesenchymal conditions that range from purely melanocytic lesions (dermal melanocytosis and blue nevi), to varied proportions of melanocytic and neuromesenchymal elements (cellular blue nevi, desmoplastic melanomas, and Bednar tumors), to purely mesenchymal lesions (DFSP).

\section{Epithelial marker expression}

Some melanomas have been observed to express CK which had been considered a specific marker for epithelial differentiation. One restrospective study described expression of CK in five of 19 melanomas analyzed. ${ }^{199}$ Other studies have shown similar results, including in the context of the demonstration of proteins by Western blot analysis that migrated to positions correlating with CK. ${ }^{200}$ This suggests that such melanomas are actually expressing CKs rather than some other explanation for spurious expression, such as impure polyclonal antibodies or crossreactivity attributed to specific monoclonal antibodies. ${ }^{200}$ This epithelial differentiation may be important as keratins coexpressed with vimentin have been correlated to invasive and metastatic potential. ${ }^{201}$ Epithelial membrane antigen is expressed in some $2-10 \%$ of melanomas studied (Figure 38).

\section{Fibrohistiocytic differentiation}

Fibrohistiocytic differentiation is demonstrated in desmoplastic melanoma. This variant of melanoma shows features in common with the DFSP as discussed above, being composed of elongated spindle-shaped cells resembling fibroblasts, surrounded by mature collagen bundles. Desmoplastic melanomas have been reported to be misdiagnosed as other soft tissue tumors such as malignant fibrous histiocytoma, atypical fibroxanthoma, and myxofibrosarcoma. They can be differentiated from these soft tissue tumors by the presence of S-100 protein. A rare example of melanocytic tumors such as the Spitz's nevus expresses CD68 (Figure 39).

\section{Smooth muscle differentiation}

Smooth muscle and osteocartilagenous differentiation are exceedingly rare phenotypes exhibited by melanoma. ${ }^{112,202}$ There have been several studies showing expression of muscle actin proteins in melanoma with up to $52 \%$ of desmoplastic melanomas being positive. However, there has been only one study showing ultrastructural smooth muscle differentiation with fine filaments and focal densities. These cells, interestingly, lost reactivity to HMB-45 and S-100. ${ }^{202}$ Osteocartilagenous differentiation usually occurs in acral, particularly subungual, lesions. They typically show osteoid matrix and occasionally chrondroblastic differentiation. They are S-100 and HMB-45 positive.

\section{Absence of melanocyte differentiation markers}

Occasionally melanomas may not express certain of the melanocyte lineage-specific markers. For example S100 protein is widely misconstrued to be ubiquitously expressed by melanomas. However, in one study 17 cases of melanoma that previously tested negative for S100 protein expression were re-evaluated by light microscopy, a broad panel of immunohistochemical reagents including monoclonal and polyclonal antibodies to S-100 protein, and electron microscopy. ${ }^{203}$ On re-examination, four of the 17 cases repeatedly tested negative for S100 protein despite various antigen enhancement methods, but they were positive for HMB-45 antigen and contained premelanosomes or melanosome-like structures by electron microscopy. Two of these repeatedly S-100-negative melanomas were acrally located; although the numbers are small, a possible relationship to a specific anatomic location was suggested. These findings suggested that in a small subset of melanomas S100 protein is either not expressed or is expressed at a level below that which can be detected by routine immunohistochemistry. In our hands, we have seen several cases of lentigo maligna in which the neoplastic melanocytes were Melan-A but not S100 protein positive. HMB-45 and Melan A detect respectively the tyrosinosome matrix-related protein gp100 and the tyrosinase pathway antigen A103. ${ }^{19}$ Both markers, like Mit-f, are much less sensitive than S100 protein expres- 


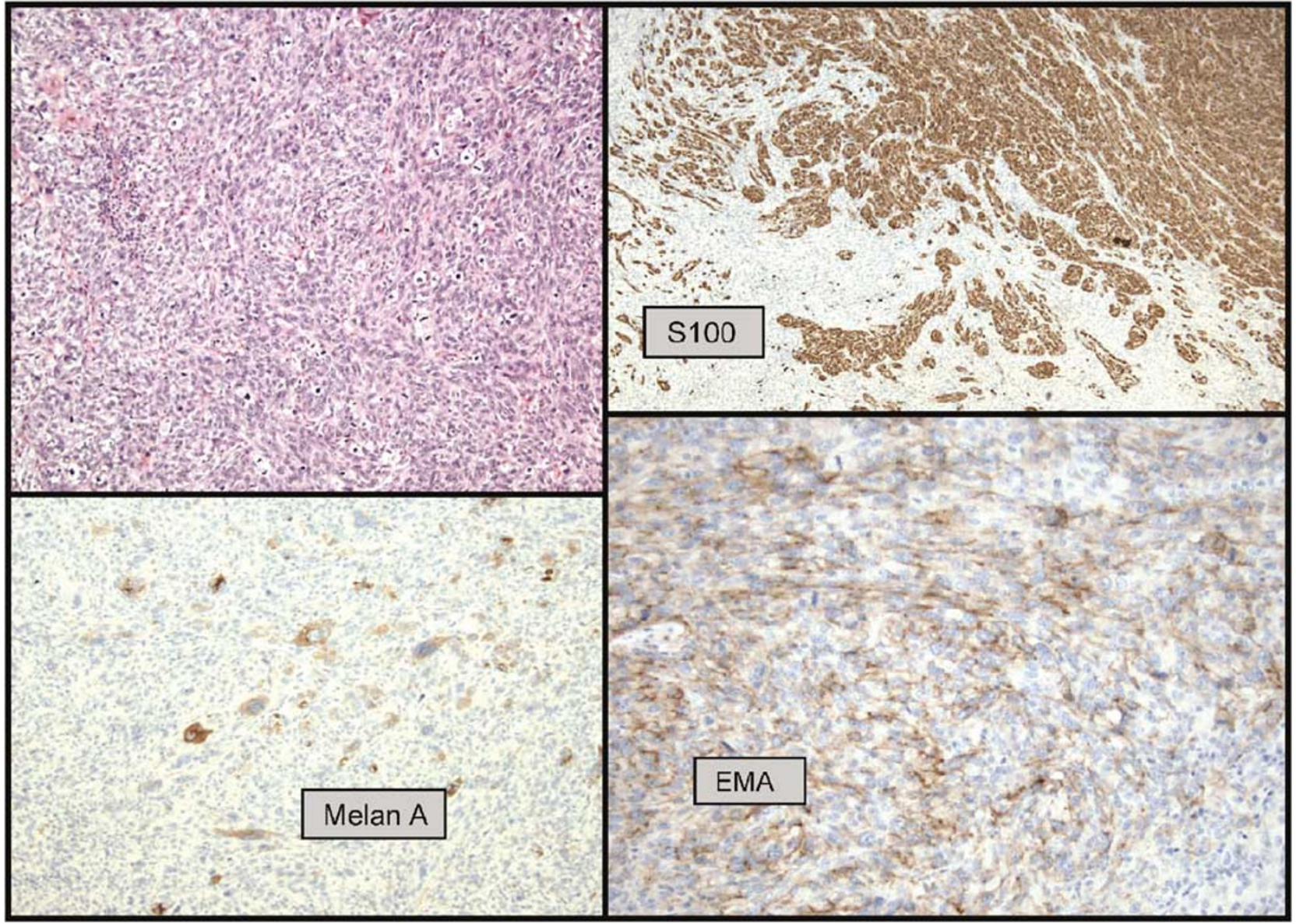

Figure 38 Aberrant expression of epithelial membrane antigen in melanoma. This melanoma shows florid S100 protein expression; only some $1-5 \%$ of cells express Melan-A. A larger number express epithelial membrane antigen.

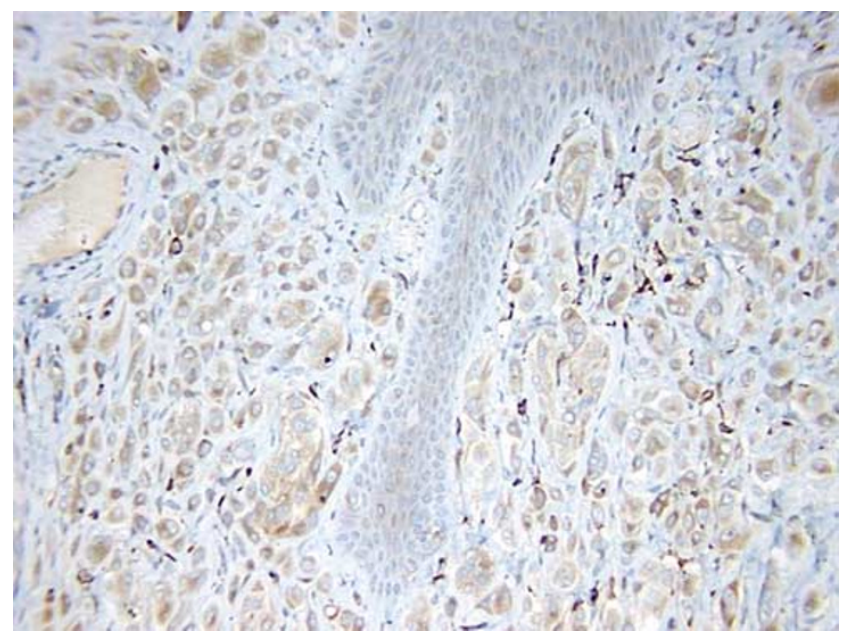

Figure 39 CD-68 expression in a Spitz's nevus. There is diffuse expression of the histiocyte marker CD-68 in this example of a Spitz's nevus. The tumor also expressed Melan-A and S100 protein, however, and had a more or less classical histomorphology, enabling diagnosis.

sion and are often negative in melanoma. Orchard ${ }^{204}$ suggests that $25 \%$ of conventional melanomas are negative for HMB- 45 as are as many as as $50 \%$ of metastatic melanomas. Desmoplastic melanomas are often negative for HMB-45 unless a junctional component is present. In regards to tyrosinase and Melan-A both have been reported to lose expression progressively in melanoma from clinical stages I to IV.

\section{References}

1 Conley J, Lattes R, Orr W. Desmoplastic malignant melanoma (a rare variant of spindle cell melanoma). Cancer 1971;28:914-936.

2 Bruijn JA, Mihm Jr MC, Barnhill RL. Desmoplastic melanoma. Histopathology 1992;20:197-205.

3 Wharton JM, Carlson JA, Mihm Jr MC. Desmoplastic malignant melanoma: diagnosis of early clinical lesions. Hum Pathol 1999;30:537-542.

4 Egbert B, Kempson R, Sagebiel R. Desmoplastic malignant melanoma. A clinicopathologic study of 25 cases. Cancer 1988;62:2033-2041.

5 Skelton HG, Smith KJ, Laskin WB, et al. Desmoplastic malignant melanoma. J Am Acad Dermatol 1995;32: 717-725.

6 Carlson JA, Dickersin GR, Sober AJ, et al. Desmoplastic neurotropic melanoma. A clinicopathologic analysis of 28 cases. Cancer 1995;75:478-494. 
7 Mulvany NJ, Sykes P. Desmoplastic melanoma of the vulva. Pathology 1997;29:241-345.

8 Kurihara K, Sanada E, Yasuda S, et al. Desmoplastic melanoma of the gingiva. Oral Surg Med Oral Pathol 1992;74:201-205.

9 Reed R, Leonard D. Neurotropic melanoma. A variant of desmoplastic melanoma. Am J Surg Pathol 1979;3: 301-311.

10 Reiman HM, Goellner JR, Woods JE, et al. Desmoplastic melanoma of the head and neck. Cancer 1987; 60:2269-2274

11 Walsh NM, Roberts JT, Orr W, et al. Desmoplastic malignant melanoma. A clinicopathological study of 14 cases. Arch Pathol Lab Med 1988;112:922-927.

12 Jain S, Allen PW. Desmoplastic malignant melanoma and its variants. Am J Surg Pathol 1989;13:358-373.

13 Beenken S, Byers R, Smith JL, et al. Desmoplastic melanoma. Histological correlation with behaviour and treatment. Arch Otolaryngol Head Neck Surg 1989;115:374-379.

14 Smithers BM, McLeod GR, Little JH. Desmoplastic, neural transforming and neurotropic melanoma: a review of 45 cases. Aust NZ J Surg 1990;60:967-972.

15 Quinn MJ, Crotty KA, Thompson JF, et al. Desmoplastic and desmoplastic neurotropic melanoma: experience with 280 patients. Cancer 1998;83:1128-1135.

16 Smithers BM, McLeod GR, Little JH. Desmoplastic melanoma: patterns of recurrence. World J Surg 1992; 16:186-190.

17 Tsao H, Sober AJ, Barnhill RL. Desmoplastic neurotropic melanoma. Semin Cutan Med Surg 1997;16: 131-136.

18 Sangueza OP, Requena L. Neoplasms with neural differentiation: a review. Am J Dermatopathol 1998; 20:89-102.

19 Crowson AN, Magro CM, Mihm Jr MC. The Melanocytic Proliferations: A Comprehensive Textbook of Pigmented Lesions. John Wiley and sons: New York, 2001, pp 281-397.

20 Moreno A, Lamarca J, Martinez R, et al. Osteoid and bone formation in desmoplastic malignant melanoma. J Cutan Pathol 1986;13:128-134.

21 Hawkins WG, Busam KJ, Ben-Porat L, et al. Desmoplastic melanoma: a pathologically and clinically distinct form of cutaneous melanoma. Ann Surg Oncol 2005;12:197-199.

22 Barnhill RL. Pathology of Melanocytic Nevi and Malignant Melanoma. Butterworth-Heinemann: Boston, 1995, pp 216-224.

23 Mihm Jr MC, Googe PB. Problematic Pigmented Lesions. A Case Method Approach. Lea and Febiger: Philadelphia, 1990, pp 279-370.

24 Barnhill RL, Mihm MC. Cellular neurothekeoma: a distinctive variant of neurothekeoma mimicking nevomelanocytic tumors. Am J Surg Pathol 1990;14:113-120.

25 Ackerman AB, Godomski J. Neurotropic malignant melanoma and other neurotropic neoplasms in the skin. Am J Dermatopathol 1984;6(Suppl 1):63-80.

26 From L, Hanna W, Kahn HJ, et al. Origin of the desmoplasia in desmoplastic malignant melanoma. Hum Pathol 1983;14:1072-1080.

27 Valensi QJ. Desmoplastic malignant melanoma. A light and electron microscopic study of two cases. Cancer 1979;43:1148-1155.

28 Valensi QJ. Desmoplastic malignant melanoma. Study of a case by light and electronmicroscopy. J Dermatol Surg Oncol 1979;5:31-35.
29 Wick MR, Swanson PE, Rocamora A. Recognition of malignant melanoma by monoclonal antibody HMB45: an immunohistochemical study of 200 paraffinembedded cutaneous tumors. J Cutan Pathol 1988;15: 201-207.

30 Anstey A, Cerio R, Ramnarain N, et al. Desmoplastic malignant melanoma. Am J Dermatopathol 1994;16: 14-22.

31 Longacre TA, Egbert BM, Rouse RV. Desmoplastic and spindle cell melanoma. An immunohistochemical study. Am J Surg Pathol 1996;20:1489-1500.

32 Busam KJ, Zhao H, Coit DG, et al. Distinction of desmoplastic melanoma from non-desmoplastic melanoma by gene expression profiling. J Invest Dermatol 2005;124:412-833.

33 Iwamoto S, Odland PB, Piepkorn M, et al. Evidence that the p75 neurotrophin receptor mediates perineural spread of desmoplastic melanoma. J Am Acad Dermatol 1996;35(5 Part 1):725-731.

34 al Alousi S, Carlson JA, Blessing K, et al. Expression of basic fibroblast growth factor in desmoplastic melanoma. J Cutan Pathol 1996;23:118-125.

35 Winnepenninckx V, De Vos R, Stas M, et al. New phenotypic and ultrastructural findings in spindle cell (desmoplastic/neurotropic) melanoma. Appl Immunohistochem Mol Morphol 2003;11:319-325.

36 King R, Googe PB, Weilbaecher KN, et al. Microphthalmia transcription factor expression in cutaneous benign, malignant melanocytic, and non-melanocytic tumors. Am J Surg Pathol 2001;25:512-557.

37 Busam KJ, Iversen K, Coplan KC, et al. Analysis of microphthalmia transcription factor expression in normal tissues and tumors, and comparison of its expression with S100 protein, gp100, and tyrosinase in desmoplastic melanoma. Am J Surg Pathol 2001; 25:197-204.

38 Busam KJ, Kucukgol D, Sato E, et al. Immunohistochemical analysis of novel monoclonal antibody PNL2 and comparison with other melanocyte differentiation markers. Am J Surg Pathol 2005;29:400-406.

39 Sagebiel RW. Unusual variants of melanoma: Fact or fictioin? Semin Oncol 1996;23:703-708.

40 Schmoeckel C, Castro CE, Braun-Falco O. Nevoid malignant melanoma. Arch Derm Res 1985;277:362369.

41 Levene A. On the histological diagnosis and prognosis of malignant melanoma. J Clin Pathol 1980;33:101-124.

42 Suster S, Ronnen M, Bubis JJ. Verrucous pseudonevoid melanoma. J Surg Oncol 1987;36:134-137.

43 Blessing K, Grant JJ, Sanders DS, et al. Small cell malignant melanoma: a variant of naevoid melanoma. Clinicopathological features and histological differential diagnosis. J Clin Pathol 2000;53:591.

44 Wong TY, Duncan LM, Mihm Jr MC. Melanoma mimicking dermal and Spitz's nevus ('nevoid melanoma'). Semin Surg Oncol 1993;9:188-193.

45 Wong TY, Suster S, Duncan LM, et al. Nevoid melanoma: a clinicopathological study of seven cases of malignant melanoma mimicking spindle and epithelioid cell nevus and verrucous dermal nevus. Hum Pathol 1995;26:171-179.

46 Kossard S, Wilkinson B. Small cell (naevoid) melanoma: a clinicopathologic study of 131 cases. Australas J Dermatol 1997;38(Suppl 1):S54-S58.

47 McNutt NS, Urmacher C, Hakimian J, et al. Nevoid malignant melanoma: morphologic patterns an immuno- 
histochemical reactivity. J Cutan Pathol 1995;22: 502-517.

48 Zembowicz A, McCusker M, Chiarelli C, et al. Morphological analysis of nevoid melanoma: a study of 20 cases with a review of the literature. Am J Dermatopathol 2001;23:167-175.

49 Muhlbauer J, Margolis R, Mihm MC, et al. Minimal deviation melanoma: a histologic variant of cutaneous malignant melanoma in vertical growth phase. J Invest Dermatol 1983;80:63s-65s.

50 Philips ME, Margolis RJ, Merot Y, et al. Common and uncommon melanocytic nevi and borderline melanomas. Semin Oncol 1975;2:119-147.

51 Reed RJ. Minimal deviation melanoma. Hum Pathol 1990;21:1206-1211.

52 Reed RJ, Martin P. Variants of melanoma. Semin Cutan Med Surg 1997;16:137-158.

53 Okun MR, DiMattia A, Thompson J, et al. Malignant melanoma developing from intradermal nevi. A clinicopathologic entity. Arch Dermatol 1974;110: 559-601.

54 Kossard S, Wilkinson B. Nucleolar organizer regions and image analysis nuclear morphometry of small cell (nevoid) melanoma. J Cutan Pathol 1995;22:132-136.

55 Philips ME, Margolis RJ, Merot Y, et al. The spectrum of minimal deviation melanoma: a clinicopathologic study of 21 cases. Hum Pathol 1986;17:796-806.

56 Podnos YD, Jimenez JC, Zainabadi K, et al. Minimal deviation melanoma. Cancer Treat Rep 2002;28:219-221.

57 Becker Jr DW, Miller CJ, Keller HB. Metastatic minimal-deviation melanoma. Ann Plast Surg 1980; 4:230-237.

58 Donner LR, Manriquez M, Greene Jr JF. Minimal deviation spindle cell melanoma: unusual histologic pattern in an 11-year-old black girl. Pediatr Pathol 1988;8:401-407.

59 Reed RJ. Minimal deviation melanoma. Borderline and intermediate melancoytic neoplasia. Clin Lab Med 2000;20:745-758.

60 Reed R, Ichinose H, Clark WC, et al. Common and uncommon melanocytic nevi and borderline melanomas. Semin Oncol 1975;2:119-147.

61 Merot Y, Mihm MC. Unusual and unknown aspect of cutaneous malignant melanoma: minimal deviation malignant melanoma. Retrospective study of 45 cases. Ann Dermatol Venereol 1985;112:325-336.

62 Chorny JA, Barr RJ, Kyshtoobayeva A, et al. Ki-67 and p53 expression in minimal deviation lesions as compared with other nevomelanocytic lesions. Mod Pathol 2003;16:525-529.

63 Levene A. Equine melanotic disease. Tumori 1971;57: 133-168.

64 Lerner AB, Cage GW. Melanomas in horses. Yale J Biol Med 1973;46:646-649.

65 Tuthill RJ, Clark WH, Levene A. Pilar neurocristic hamartoma. Its relationship to blue nevus and equine melanotic disease. Arch Dermatol 1982;118:592-596.

66 Rappaport H, Pietra G, Shubick P. The induction of melanotic tumors resembling cellular blue nevi in the Syrian hamster by cutaneous application of 7,12-dimethylbenz-(a)-anthracene. Cancer Res 1961; 21:661-666.

67 Walters MA, Roe FJC, Levene A. The induction of tumors and other lesions in hamsters by a single subcutaneous injection of 9,10-dimethyl-1,2-benzanthracene or urethane on the first day of life. Br J Cancer 1967;21:184-189.
68 Nakai T, Rappaport H. A study of the histogenesis of experimental melanocytic tumors resembling cellular blue nevi: the evidence in support of their neurogenic origin. Am J Pathol 1963;43:175-199.

69 Epstein JH, Epstein WL, Nakai T. Production of melanomas from DMBA-induced 'blue nevi' in hairless mice with ultraviolet light. J Nat Cancer Inst 1967;38:19-30.

70 Darier J. Le melanome malin mesenchymateaux ou melano-sarcome. Bull Assoc Fr Cancer 1925;14: 221-249.

71 Crowson AN, Magro CM, Mihm Jr MC. Malignant melanoma with prominent pigment synthesis: 'animal type' melanoma. Hum Pathol 1999;30:543-550.

72 Levene A. Disseminated dermal melanocytosis terminating in melanoma: a human condition resembling equine melanotic disease. Br J Dermatol 1979;101: 197-205.

73 Pathy AL, Helm TN, Elston D, et al. Malignant melanoma arising in a blue nevus with features of pilar neurocristic hamartoma. J Cutan Pathol 1993;20: 459-464.

74 Crowson AN, Magro CM, Clark WH. Pilar neurocristic hamartoma (letter). J Am Acad Dermatol 1996;34:715.

75 Kopf AW, Bart RS. Malignant blue (Ota's?) nevus. J Dermatol Surg Oncol 1982;8:442-445.

76 Mehregan DA, Gibson LE, Mehregan AH. Malignant blue nevus: a report of eight cases. J Dermatol Sci 1992;4:185-192.

77 Van Krieken JH, Boom BW, Scheffer E. Malignant transformation in a naevus of Ito: a case report. Histopathology 1988;12:100-102.

78 Levene A. On the natural history and comparative pathology of the blue naevus. Ann R Coll Surg Engl 1980;62:327-334.

79 Rodriguez HA, Ackerman LV. Cellular blue nevus: clinicopathologic study of forty-five cases. Cancer 1968;21:393-405.

80 Silverberg GD, Kadin ME, Dorfman RF, et al. Invasion of the brain by a cellular blue nevus of the scalp. A case report with light and electron microscopic studies. Cancer 1971;27:349-355.

81 Sterchi JM, Muss HB, Weidner N. Cellular blue nevus simulating metastatic melanoma: report of an unusually large lesion associated with nevus-cell aggregates in regional lymph nodes. J Surg Oncol 1987;36:71-75.

82 Lach B, Russell N, Benoit B, et al. Cellular blue nevus ('melanocytoma') of the spinal meninges: electron microscopic and immunhistochemical features. Neurosurgery 1988;22:773-780.

83 Kaburagi Y, Hatta N, Kawara S, et al. Pigmented dermatofibrosarcoma protuberans (Bednar tumor) occurring in a Japanese patient. Dermatology 1998; 197:48-51

84 Zembowicz A, Carney JA, Mihm MC. Pigmented epithelioid melanocytoma: a low grade melanocytic tumor with metastatic potential indistinguishable from animal-type melanoma and epithelioid blue nevus. Am J Surg Pathol 2004;28:31-40.

85 Zembowicz A, Mihm MC. Pigment synthesizing melanocytic tumor: a low grade melanocytic tumor with frequent lymph node metastases (Abst). Lab Invest 2002, 112A.

86 Allen AC, Spitz S. Malignant melanoma: a clinicopathologic analysis of the criteria for diagnosis and prognosis. Cancer 1953;6:1-45. 
87 Merkow LP, Burt RC, Hayeslip DW, et al. A cellular and malignant blue nevus: a light and electron microscopic study. Cancer 1969;24:888-896.

88 Mishima Y. Cellular blue nevus: melanogenic activity and malignant transformation. Arch Dermatol 1970; 101:104-110.

89 Okun MR. Malignant blue nevus (letter). Arch Dermatol 1973;108:726-727.

90 Hernandez FJ. Malignant blue nevus: a light and electron microscopic study. Arch Dermatol 1973;107: 741-744.

91 Reiss RF, Gray Jr GF. Malignant blue nevus. Occurrence with aggressive behavior. NY State J Med 1975;75:1749-1751.

92 Temple-Camp CRE, Saxe N, King H. Benign and malignant cellular blue nevus: a clinicopathological study of 30 cases. Am J Dermatopathol 1988;10:289-296.

93 Goldenhersh MA, Savin RC, Barnhill RL, et al. Malignant blue nevus. Case report and literature review. J Am Acad Dermatol 1988;19:712-722.

94 Connelly J, Smith JL. Malignant blue nevus. Cancer 1991;67:2653-2657.

95 Aloi F, Pich A, Pippione M. Malignant cellular blue nevus: a clinicopathological study of 6 cases. Dermatology 1996;192:36-40.

96 Duteille F, Duport G, Larregue M, et al. Malignant blue nevus: three new cases and a review of the literature. Ann Plast Surg 1998;41:674-678.

97 Ariyanayagam-Baksh SM, Baksh FK, Finkelstein SD, et al. Malignant blue nevus. A case report and molecular analysis. Am J Dermatopathol 2003;25:21-27.

98 Ozgur F, Akyurek M, Kayikcioglu A, et al. Metastatic malignant blue nevus: a case report. Ann Plast Surg 1997;39:411-415.

99 Biernat W, Kordek R, Arkuszewska C, et al. Malignant blue nevus with neurosarcoma-like lymph node metastases. Pol J Pathol 1995;46:51-54.

100 English III JC, McCollough ML, Grabski WJ. A pigmented scalp nodule: malignant blue nevus. Cutis 1996;58:40-42.

101 Nödl F, Krüger R. Maligner blauer Navus bei Navus Ota. Hautartz 1984;35:421-424.

102 Yoneyama K, Kamada N, Mizoguchi M, et al. Malignant melanoma and acquired dermal melanocytosis on congenital nevus spilus. J Dermatol 2005;32:454-458.

103 Avidor I, Kessler E. 'Atypical' blue nevus-a benign variant of cellular blue nevus. Presentation of three cases. Dermatologica 1977;154:39-44.

104 Tran TA, Carlson JA, Basaca PC, et al. Cellular blue nevus with atypia (atypical cellular blue nevus): a clinicopathologic study of nine cases. J Cutan Pathol 1998;25:252-258.

105 Urmacher C. Unusual stromal patterns in truly recurrent and satellite metastatic lesions of malignant melanoma. Am J Dermatopathol 1984;6(Suppl): 331-335.

106 Grunwald MH, Rothem A, Feuerman EJ. Metastatic malignant melanoma with cartilaginous metaplasia. Dermatologica 1985;170:249-252.

107 Weidner N, Flanders DJ, Jochimsen PR, et al. Neurosarcomatous malignant melanoma arising in a neuroid giant congenital melanocytic nevus. Arch Dermatol 1985;121:1302-1306.

108 Moreno A, Lomarca J, Martinez R, et al. Osteoid and bone formation in desmoplastic malignant melanoma. J Cutan Pathol 1986;13:128-134.
109 Nakagawa H, Imakado S, Nogita T, et al. Osteosarcomatous changes in malignant melanoma. Am J Dermatopathol 1990;12:162-168.

110 Hoorweg JJ, Loftus BM, Hilgers FJ. Osteoid and bone formation in a nasal mucosal melanoma and its metastasis. Histopathology 1987;31:465-468.

111 Toda S, Heasley DD, Mihm MC. Osteogenic melanoma: stromal metaplasia in association with subungual melanoma. Histopathology 1997;31:293-295.

112 Cachia AR, Kedziora AM. Subungual melanoma with cartilaginous differentiation. Am J Dermatopathol 1999;21:165-169.

113 Hendrickson MR, Ross JC. Neoplasms arising in congenital giant nevi: morphological study of seven cases and a review of the literature. Am J Surg Pathol 1981;5:109-135.

114 Perniciaro C. Dermatopathologic variants of malignant melanoma. Mayo Clin Proc 1997;72:273-279.

115 Kao GF, Helwig EB, Graham JH. Balloon cell malignant melanoma of the skin. A clinicopathologic study of 34 cases with histochemical, immunohistochemical, and ultrastructural observations. Cancer 1992; 69:2942-2952.

116 Adamek D, Kaluza J, Stachura K. Primary balloon cell malignant melanoma of the right temporo-parieta region arising from meningeal naevus. Clin Neuropathol 1995;14:29-32.

117 Van der Linde-Sipman JS, de Wit MM, van Garderen $\mathrm{E}$, et al. Cutaneous malignant melanomas in 57 cats: identification of (amelanotic) signet-ring and balloon cell types and verification of their origin by immunohistochemistry, electron microscopy, and in situ hybridization. Vet Pathol 1997;34:31-38.

118 Mowat A, Reid R, Mackie R. Balloon cell metastatic melanoma: an important differential in the diagnosis of clear cell tumors. Histopathology 1994;24:469-472.

119 Riley FC. Balloon cell melanoma of the choroid. Arch Ophthalmol 1974;92:131-133.

120 Khalil MK. Balloon cell malignant melanoma of the choroid: ultrastructural studies. Br J Ophthalmol 1983;67:579-584.

121 Nowak M, Fatteh S, Campbell T. Glycogen-rich malignant melanomas and glycogen-rich balloon cell malignant melanomas: frequency and pattern of PAS positivity in primary and metastatic melanomas. Arch Pathol Lab Med 1998;122:353-360.

122 Perez MT, Suster S. Balloon cell change in cellular blue nevus. Am J Dermatopathol 1999;21: 181-184.

123 Martinez F, Merenda G, Bedrossian CW. Lipid-rich metastatic balloon-cell melanoma: diagnosis by a multimodal approach to aspiration biopsy cytology. Diagn Cytopathol 1990;6:427-433.

124 Aloi FG, Coverlizza S, Pippione M. Balloon cell melanoma: a report of two cases. J Cutan Pathol 1988;15:230-233.

125 Gregel C, Wolter M, Kaufmann R. Co-existence of balloon cell melanoma with balloon cells in a dermal nevus. Pathologe 1998;19:151-153.

126 Wambacher-Gaser B, Zelger B, Zelger BG, et al. Clear cell dermatofibroma. Histopathology 1997;30:64-69.

127 Terayama K, Hirokawa M, Shimizu M, et al. Balloon melanoma cells mimicking foamy histiocytes. Acta Cytol 1999;43:325-326.

128 Nakleh RE, Wick MR, Rocamora A, et al. Morphological diversity in malignant melanomas. Am J Clin Pathol 1990;93:731-840. 
129 Tsang WY, Chan JK, Chow LT. Signet-ring melanoma mimicking adenocarcinoma. A case report. Acta Cytol 1983;37:559-562.

130 Simmons TJ, Martin SE. Fine-needle aspiration biopsy of malignant melanoma: a cytologic and immunocytochemical analysis. Diagn Cytopathol 1991;7:380-386.

131 Neimann TH, Thomas PA. Melanoma with signet-ring cells in a peritoneal effusion. Diagn Cytopathol 1995; 12:241-244.

132 Al-Talib RK, Theaker JM. Signet-ring melanoma: light microscopic, immunohistochemical and ultrastructural features. Histopathology 1991;18:572-575.

133 Eckert F, Baricevic B, Landthaler M, et al. Metastatic signet-ring melanoma in a patient with an unkown primary tumor. Histologic, immunohistochemical and ultrastructural findings. J Am Acad Dermatol 1992;26(5 Part 2):870-875.

134 Sheibani K, Battifora H. Signet-ring cell melanoma. A rare morphologic variant of malignant melanoma. Am J Surg Pathol 1988;12:28-34.

135 Rutten A, Huschka U, Requena C, et al. primary cutaneous signet-ring melanoma: a clinicopathologic and immunohistochemical study of two cases. Am J Dermatopathol 2003;25:418-422.

136 Bonetti F, Colombari R, Zamboni G, et al. Signet ring melanoma, S-100 negative. Am J Surg Pathol 1989; 13:522-523.

137 Hanna W, Kahn HJ, From L. Signet ring lymphoma of the skin: ultrastructural and immunohistochemical features. J Am Acad Dermatol 1986;14(2 Part 2):344-350.

138 LiVolsi VA, Brooks JJ, Soslow R, et al. Signet ring melanocytic lesions. Mod Pathol 1992;5:515-520.

139 Collina G, Losi L, Taccagni GL, et al. Myxoid metastases of melanoma: report of three cases and review of the literature. Am J Dermatopathol 1997; 19:52-57.

140 Nottingham JF, Slater DN. Malignant melanoma: a new mimic of colloid adenocarcinoma. Histopathology 1988;13:576-578.

141 Urso C, Giannotti B, Bondi R. Myxoid melanoma of the skin. Arch Pathol Lab Med 1990;114:527-528.

142 Garcia-Caballero T, Fraga M, Antunez JR, et al. Myxoid metastatic melanoma. Histopathology 1991; 18:371-373.

143 Sarode VR, Joshi K, Ravichandran P, et al. Myxoid variant of primary cutaneous malignant melanoma. Histopathology 1992;20:186-187.

144 Prieto VG, Kanik A, Salob S, et al. Primary cutaneous myxoid melanoma: immunohistologic clues to a difficult diagnosis. J Am Acad Dermatol 1994;30(2 Part 2):335-339.

145 McCluggage WG, Shah V, Toner PG. Primary cutaneous myxoid malignant melanoma. Histopathology 1996;28:179-182.

146 Zelger BG, Steiner H, Wambacher B, et al. Malignant melanomas simulating various types of soft tissue tumors. Dermatol Surg 1997;23:1047-1054.

147 Hitchcock MG, McCalmont TH, White WL. Cutaneous melanoma with myxoid features. Am J Surg Pathol 1999;23:1506-1513.

148 Chetty R, Slavin JL, Pitson GA, et al. Melanoma botryoides: a distinctive myxoid pattern of sino-nasal melanoma. Histopathology 1994;24:377-379.

149 Rocamora A, Carrillo R, Vives R, et al. Fine needle aspiration biopsy of myxoid metastasis of malignant melanonma. Acta Cytol 1988;32:94-100.
150 Lindholm K, de la Torre M. Fine needle aspiration cytology of myxoid metastatic melanoma. Acta Cytol 1988;32:719-721.

151 Olinici CD, Vasiu R. Myxoid malignant melanoma. Report of three cases and review of the literature. Morphol Embryol (Bucur) 1989;35:285-287.

152 Lodding P, Kindblom LG, Angervall L. Metastases of malignant melanoma simulating soft tissue sarcoma. A clinico-pathological, light- and electron microscopic and immunohistochemical study of 21 cases. Virchows Arch A Pathol Anat Histopathol 1990;417: 377-388.

153 Auger M, Caraway NP, Wojcik EM, et al. Fine needle aspiration biopsy of metastatic myxoid melanoma. Cytopathology 1994;5:118-122.

154 Hitchcock MG, White WL. Malicious masquerade: myxoid melanoma. Semin Diagn Pathol 1998;15: 195-202.

155 Kim YC, Vandersteen DP, Juang HG. Myxoid clear cell sarcoma. Am J Dermatopathol 2005;27:51-55.

156 LaMar WL, Crowson AN. Malignant melanoma with prominent myxoid stroma ('myxoid melanoma'). Melanoma Res 2001;11(Suppl 1):S58.

157 Patel SR, Burgess MA, Plager C, et al. Myxoid liposarcoma. Experience with chemotherapy. Cancer 1994;74:1265-1269.

158 Patel SR, Burgess MA, Papadopoulos NE, et al. Extraskeletal myxoid chondrosarcoma. Long-term experience with chemotherapy. Am J Clin Oncol 1995;18:161-163.

159 Shidham VB, Ayala GE, Lahaniatis JE, et al. Low grade fibromyxoid sarcoma: clincopathologic case report with review of the literature. Am J Clin Oncol 1999;22:150-155.

160 Lindberg GM, Maitra A, Gokaslan ST, et al. Low grade fibromyxoid sarcoma: fine-needle aspiration cytology with histologic, cytogenetic, immunohistochemical and ultrastructural correlation. Cancer 1999; 87:75-82.

161 Mentzel T, Dry S, Katenkamp D, et al. Low grade myofibroblastic sarcoma. Analysis of 18 cases in the spectrum of myofibroblastic tumors. Am J Surg Pathol 1998;22:1228-1238.

162 Meiss-Kindblom JM, Bergh P, Gunterberg B, et al. Extraskeletal myxoid chondrosarcoma: a reappraisal of its morphological spectrum and prognostic factors based upon 117 cases. Am J Surg Pathol 1999; 23:636-650.

163 Bhuta S, Mirra J, Cochran A. Myxoid malignant melanoma. A previously undescribed histologic pattern noted in metastatic lesions and a report of four cases. Am J Surg Pathol 1986;10:203-211.

164 Hinze P, Feyler S, Berndt J, et al. Malignant myoepithelioma of the vulva resembling a rhabdoid tumour. Histopathology 1999;35:50-54.

165 Krane JF, Bertoni F, Fletcher CD. Myxoid synovial sarcoma: an underappreciated morphological subset. Mod Pathol 1999;12:456-462.

166 Fisher C, Magnusson B, Hardarson S, et al. Myxoid variant of follicular dendritic cell sarcoma arising in the breast. Ann Diagn Pathol 1999;3:92-98.

167 Orlandi A, Bianchi L, Spagnoli LG. Myxoid dermatofibrosarcoma protuberans: morphological, ultrastructural and immunohistochemical features. J Cutan Pathol 1998;25:386-393.

168 Fisher C, Miettinen M. Parachordoma: a clinicopathological and immunohistochemical study of four cases 
of an unusual soft tissue neoplasm. Ann Diagn Pathol 1997;1:3-10.

169 Imlay SP, Argenyi ZB, Stone MS, et al. Cutaneous parachordoma. A light microscopic and immunohistochemical report of two cases and review of the literature. J Cutan Pathol 1998;25:279-284.

170 Folpe AL, Agoff SN, Willis J, et al. Parachordoma is immunohistochemically and cytogenetically distinct from axial chordoma and extraskeletal myxoid chondrosarcoma. Am J Surg Pathol 1999;23:1059-1067.

171 Chan JK, Buchanan R, Fletcher CD. Sarcomatoid variant of anaplastic large-cell Ki-1 lymphoma. Am J Surg Pathol 1990;14:983-988.

172 Dei Tos AP, Mentzel T, Fletcher CD. Primary liposarcoma of the skin: a rare neoplasm with unusual high grade features. Am J Dermatopathol 1998;20:332-338.

173 Sakaguchi N, Sano K, Ito M, et al. A case of von Recklinghausen's disease with bilateral pheochromocytoma-malignant peripheral nerve sheath tumors of the adrenal and gastrointestinal autonomic nerve tumors. Am J Surg Pathol 1996;20:889-897.

174 Rao UN, Surti U, Hoffner L, et al. Cytogenetic and histologic correlation of peripheral nerve sheath tumors of soft tissue. Cancer Genet Cytogenet 1996;88:17-25.

175 Flieder DB, Moran CA. Primary cutaneous synovial sarcoma: a case report. Am J Dermatopathol 1998; 20:509-512.

176 Gagne EJ, Su WP. Chordoma involving the skin: an immunohistochemical study of 11 cases. J Cutan Pathol 1992;19:469-475.

$177 \mathrm{Su}$ WP, Louback JB, Gagne EJ, et al. Chordoma cutis: a report of nineteen patients with cutaneous involvement of chordoma. J Am Acad Dermatol 1993;29:63-66.

178 Jones B, Ghosh BC, Skelton HG. Chordoma with cutaneous metastasis. Cutis 1994;54:250-252.

179 Ogi H, Kiryu H, Yori Y, et al. Cutaneous metastasis of CNS chordoma. Am J Dermatopathol 1995;17:599-602.

180 Cesinaro AM, Maiorana A, Annessi G, et al. Cutaneous metastasis of chordoma. Am J Dermatopathol 1995;17:603-605.

181 Miller SD, Vinson RP, McCullough ML, et al. Multiple smooth skin nodules. Chordoma cutis. Arch Dermatol 1997;133:1579-1580, 1582-1583.

182 Nielsen GP, O’Connell JX, Rosenberg AE. Intramuscular myxoma. A clinicopathologic study of 51 cases with emphasis on hypercellular and hypervascular variants. Am J Surg Pathol 1998;22:1222-1227.

183 Michal M. Mucinous naevoacellular nevi. Dermatopathology 1994;188:232-235.

184 Michal M, Baumrunk L, Skalova A. Myxoid change within cellular blue nevi a diagnostic pitfall. Histopathology 1992;20:527-530.

185 Husain S, Silvers DN, Halperin AJ, et al. Histologic spectrum of neurothekeoma and the value of immunoperoxidase staining for S-100 protein in distinguishing it from melanoma. Am J Dermatopathol 1994;16:496-503.

186 Ferreiro JA, Nascimento AG. Hyaline-cell rich chondroid syringioma. A tumor mimicking malignancy. Am J Surg Pathol 1995;19:912-917.

187 Abbott JJ, Amirkhan RH, Hong MP. Malignant melanoma with a rhabdoid phenotype: histologic, immunohistochemical, and ultrastructural study of a case and review of the literature. Arch Pathol Lab Med 2004;128:686-688.
188 Borek B, McKee P, Freeman J, et al. Primary malignant melanoma with rhabdoid features: A histologic and immunocytochemical study of three cases. Am J Dermatopathol 1998;20:123-127.

189 Molgaard H, Spurr N, Greaves M. The hemopoietic stem cell antigen, CD34, is encoded by a gene located on chromosome 1. Leukemia 1989;3:773-776.

190 Hoang M, Selim M, Bentley R, et al. CD34 expression in desmoplastic melanoma. J Cutan Pathol 2001;28: 508-512.

191 Aiba S, Tabata N, Ishii H, et al. Dermatofibrosarcoma protuberans is a unique fibrohistiocytic tumour expressing CD34. Br J Dermatol 1992;127:79-84.

192 Chen X, Maniotis A, Majumdar D, et al. Uveal melanoma cell staining for CD34 and assessment of tumor vascularity. Invest Ophthalmol Vis Sci 2002; 43:2533-2539.

193 Smith K, Germain M, Williams J, et al. CD34-positive cellular blue nevi. J Cutan Pathol 2001;28:145-150.

194 Maniotis A, Folberg R, Hess A, et al. Vascular channel formation by human melanoma cells in vivo and in vitro: Vasculogenic mimicry. Am J Pathol 1999; 155:739-752.

195 Nickoloff B. The human progenitor cell antigen (CD34) is localized on endothelial cells, dermal dendritic cells, and perifollicular cells in formalinfixed normal skin, and on proliferating endothelial cells and stromal spindle-shaped cells in Kaposi's sarcoma. Arch Dermatol 1991;127:523-529.

196 Hendrix M, Seftor E, Meltzer P, et al. Expression and functional significance of VE-cadherin in aggressive human melanoma cells: role in vasculogenic mimicry. Proc Natl Acad Sci USA 2001;98:8018 CD34 positive malignant melanomas.

197 Weiss S, Nickoloff B. CD-34 is expressed by a distinctive cell population in peripheral nerve, nerve sheath tumors, and related lesions. Am J Surg Pathol 1993;17:1039-1045.

198 Goncharuk V, Mulvany M, Carlson A. Bednar tumor associated with dermal melanocytosis: melanocytic colonization or neuroectodermal multidirectional differentiation? J Cutan Pathol 2003;30:147-151.

199 Banks E, Jansen J, Oberle E, et al. Cytokeratin positivity in fine-needle aspirates of melanomas and sarcomas. Diagn Cytopathol 1995;12:230-233.

200 Zarbo RJ, Gown A, Nagle R, et al. Anomalous cytokeratin expression in malignant melanoma: one and two-dimensional western blot analysis and immunohistochemical survey of 100 melanomas. Mod Pathol 1990;3:494-501.

201 Hendrix M, Seftor E, Chu Y, et al. Coexpression of vimentin and keratins by human melanoma tumor cells: correlation with invasive and metastatic potential. J Natl Cancer Inst 1992;84:165-174.

202 Banerjee S, Bishop P, Nicholson C, et al. Malignant melanoma showing smooth muscle differentiation. J Clin Pathol 1996;49:950-951.

203 Argenyi Z, Cain C, Bromley C, et al. S-100 proteinnegative malignant melanoma: fact or fiction? A lightmicroscopic and immunohistochemical study. A J Dermatopathol 1994;16:233-240.

204 Orchard GE. Comparison of immunohistochemical labeling of melanocyte differentiation antibodies melan-A, tyrosinase and HMB-45 with NKIC3 and S100 protein in the evaluation of benign naevi and malignant melanoma. Histochem J 2000;32: $475-481$. 